\title{
EFFECTS OF PRUNING LEVEL AND CANOPY MANAGEMENT PRACTICES ON BERRY MATURATION RATE AND HARVEST PARAMETERS OF SYRAH WINE GRAPES
}

\author{
A Thesis \\ presented to \\ the Faculty of California Polytechnic State University, \\ San Luis Obispo
}

\author{
In Partial Fulfillment \\ of the Requirements for the Degree \\ Master of Science in Agriculture, Specialization in Crop Science
}

by

Jeffery S. Landolt

March, 2011 
(C) 2011

Jeffery S. Landolt

ALL RIGHTS RESERVED 


\section{COMMITTEE MEMBERSHIP}

TITLE:

AUTHOR:

DATE SUBMITTED:

COMMITTEE CHAIR:

COMMITTEE MEMBER: David H. Headrick, Ph.D.

COMMITTEE MEMBER: $\quad$ Terry Smith, Ph.D.
Effects of pruning level and canopy management practices on berry maturation rate and harvest parameters of Syrah wine grapes

Jeffery Landolt

March, 2011 


\begin{abstract}
Effects of pruning level and canopy management practices on berry maturation rate and harvest parameters of Syrah wine grapes

Jeffery S. Landolt
\end{abstract}

Syrah is an important wine grape in California but is potentially difficult to manage in the vineyard due to its excessive vigor. Vigorous grapevines require more labor for canopy management and tend to create excess shade, decreasing fruit quality. Winter pruning level, shoot thinning and leaf removal influence the overall density of the canopy and the subsequent degree of shade in the fruit zone. An experiment was conducted to assess the effects of two pruning levels with three degrees of labor-intensive canopy management techniques on berry maturation rate and harvest berry parameters for two growing seasons. In 2008, repeated measures analysis showed no significant effects of severe pruning, shoot thinning or both sides leaf removal on maturation rate of performance indicators. At harvest 2008, severe pruning caused a decrease in yield/meter trellis and Ravaz index. In 2009, repeated measures analysis showed significant effects of severe pruning increasing brix, $\mathrm{pH}$ and sugar/acid ratio while shoot thinning and both sides leaf removal had no significant effects on maturation rate of performance indicators. At harvest 2009, severe pruning increased brix, $\mathrm{pH}$, tannin, anthocyanins, phenolics, color density, potassium, amino acid \% of yeast assimilable nitrogen (YAN), and the following ratios: sugar/acid, amino acid/ammonium, tannin/anthocyanins and malic/tartaric acid.

Additionally, severe pruning decreased tartaric acid, yield/meter trellis, ammonium \% of YAN and Ravaz index. The findings presented in this thesis suggest that severe pruning could be used as a tool in viticultural areas with short growing seasons because of the increased ripening speed observed. However, because severe pruning generally increases berry size which is negative for vinification, it should be studied further with irrigation and management practices that decrease berry size. 


\section{TABLE OF CONTENTS}

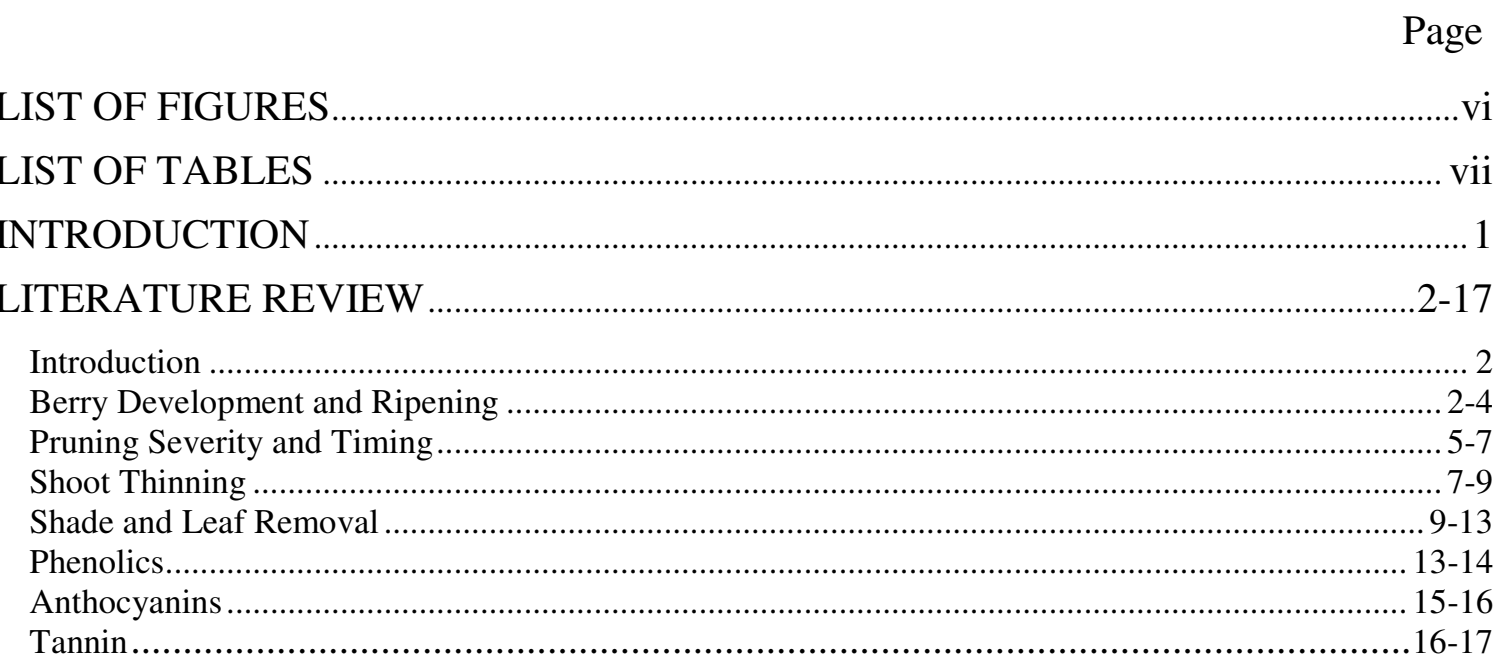

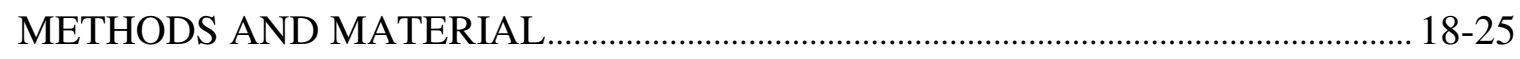

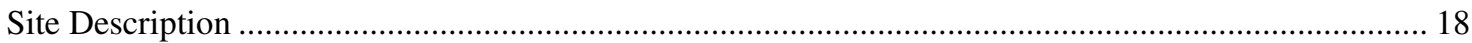

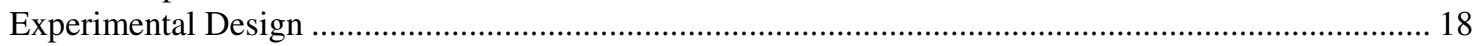

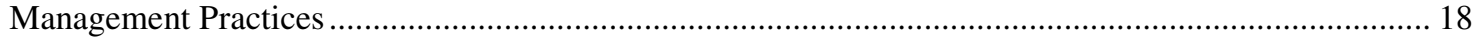

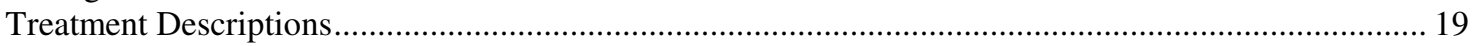

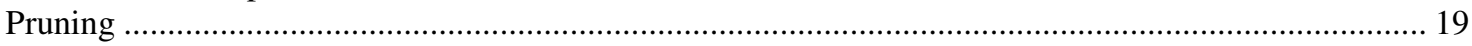

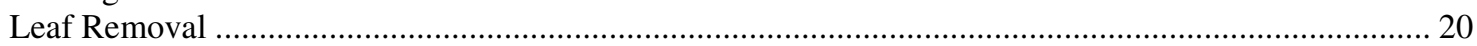

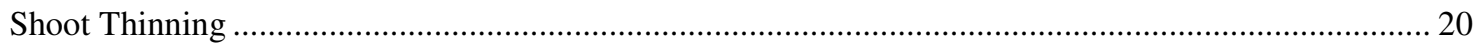

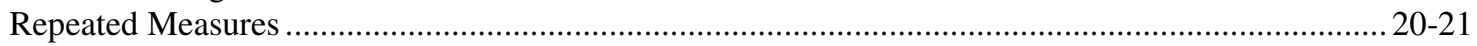

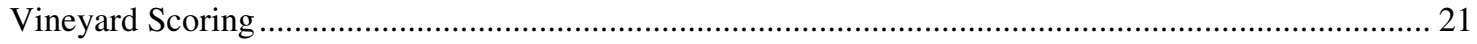

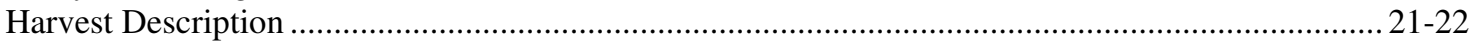

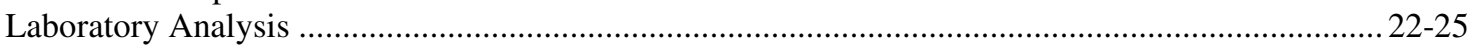

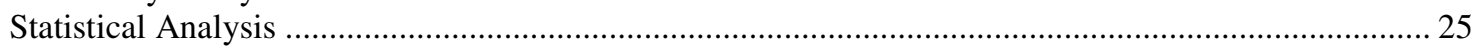

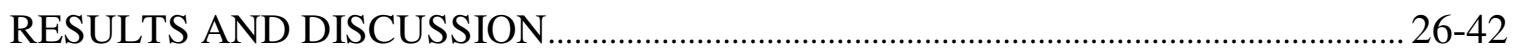

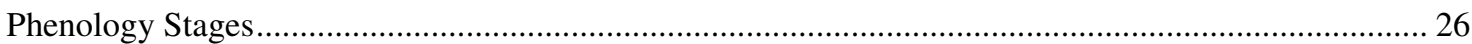

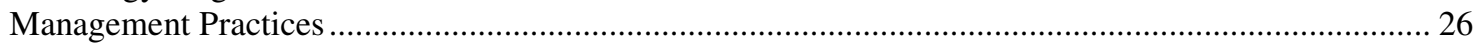

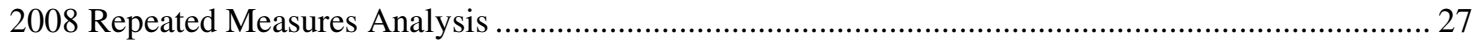

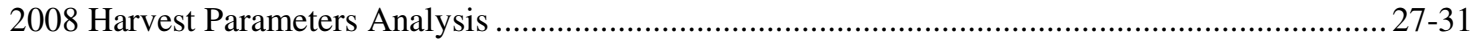

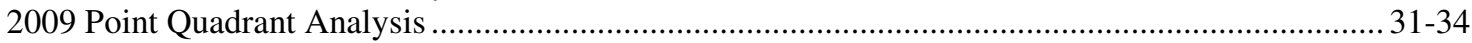

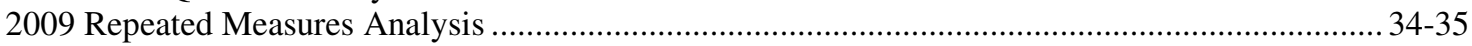

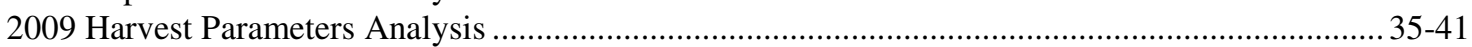

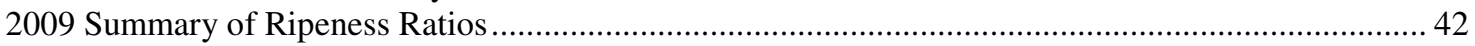

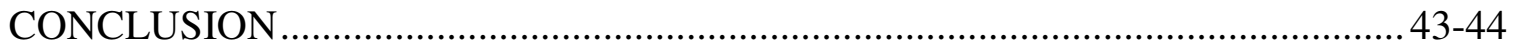

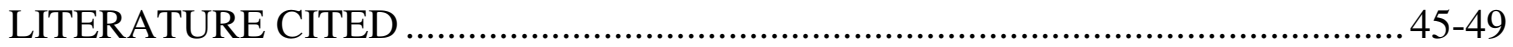

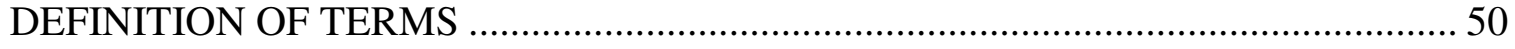

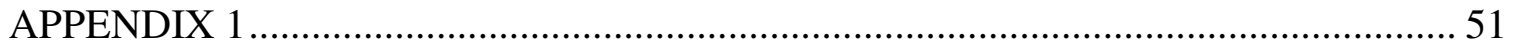

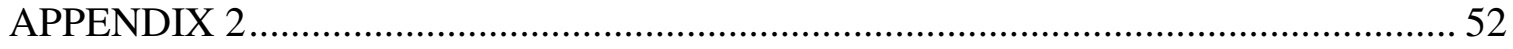

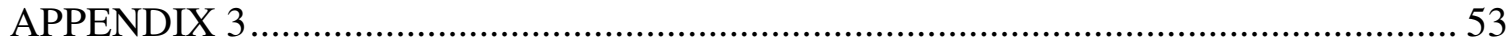

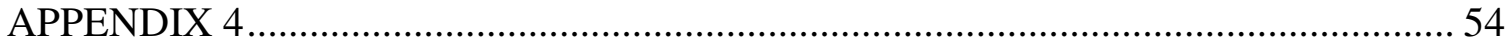




\section{LIST OF FIGURES}

Figure

Page

Figure 1. Diagram of a double sigmoid berry growth curve....................................... 3

Figure 2. Effect of pruning and canopy treatment on average cluster weight $2008 \ldots \ldots \ldots . . .28$

Figure 3. Effect of pruning and canopy treatment on berry weight 2008 ...................... 29

Figure 4. Effect of pruning and canopy treatment on average \% canopy gaps 2009 ....... 32

Figure 5. Effect of pruning and canopy treatment on average canopy leaf layers 2009 .. 33

Figure 6. Effect of pruning and canopy treatment on average \% interior leaves $2009 \ldots . .34$

Figure 7. Diagram of a standard curve for catechin................................................. 52

Figure 8. Diagram of a standard curve for malvidin ................................................ 54 


\section{LIST OF TABLES}

Table

Page

Table 1. Phenology dates for syrah grapevine at Trestle Vineyard

Table 2. Management practices dates for syrah grapevine at Trestle Vineyard 26

Table 3. Effect of pruning and canopy treatment on berry maturation rates 2008 27

Table 4. Effect of pruning and canopy treatment on yield parameters 2008 30

Table 5. Effect of pruning and canopy treatment on vine parameters 2008 31

Table 6. Effect of pruning and canopy treatment on berry maturation rates 2009 35

Table 7. Effect of pruning and canopy treatment on harvest berry chemistry $2009 \ldots \ldots . . .36$

Table 8 . Effect of pruning and canopy treatment on berry potassium \& nitrogen 2009 . 37

Table 9. Effect of pruning and canopy treatment on organic acid composition 2009 ...... 38

Table 10. Effect of pruning and canopy treatment on proanthocyanidins 2009 39

Table 11. Effect of pruning and canopy treatment on phenolics and color 2009 40

Table 12. Effect of pruning and canopy treatment on yield parameters 2009. 41

Table 13. Effect of pruning and canopy treatment on ripeness ratios 2009 42 


\section{$\underline{\text { Introduction }}$}

Syrah is an important wine grape in California and is used as a stand-alone varietal in winemaking as well as in blending. Syrah grape acreage increased in California 23\% from 2001 to 2008 (USDA, 2010). California currently has over 18,875 acres of syrah in production (USDA, 2010). San Luis Obispo County grows more syrah acres than any other county in the state with 2,714 total acres in 2008 (USDA, 2010).

Growing quality syrah wine grapes can be challenging when one considers the excessive vigor which can characterize the cultivar. Excessive vigor can lead to an increase in labor requirements for canopy management and a decrease in fruit quality due to increased shade in the canopy (Smart et al., 1985). Excess shade in the canopy results in increased levels of potassium, $\mathrm{pH}$ and malic acid as well as decreased levels of nitrogen, soluble solids and phenolics in musts (Dokoozlian and Kliewer, 1996) (Pereira et al., 2006) (Ristic et al., 2007). In a cool climate, such as San Luis Obispo, CA, the negative characteristics caused by shading are often accentuated and more care needs to be given towards assuring proper fruit exposure.

Industry-wide there has been an increase in production costs causing more efforts to be focused on input reduction, especially labor (Archer and Schalkwyk, 2007). Mechanization of many vineyard management practices has led to a decrease in production costs for some large growers with economies of scale. For growers with smaller acreage it is necessary to explore other ways to reduce labor costs where mechanization is not feasible while retaining or improving fruit quality. The focus of this research project was to investigate different combinations of pruning levels and reduced input canopy management practices on Vitis vinifera L. cv. syrah (clone 877) on 420a rootstock as a means of labor control. 


\section{Literature Review}

\section{Introduction}

The principle options available for controlling the number of shoots and the eventual density of the canopy are winter pruning and in-season shoot thinning (Smart, 1985). Additionally, leaf removal has a positive effect on light and air penetration into the canopy and decreases canopy density (Koyama and Goto-Yamamoto, 2008). High density canopies resulting from improper pruning, lack of shoot and/or leaf removal, high soil water availability, or excessive levels of available nitrogen will have a greater percentage of interior leaves relative to exterior leaves when compared to low density canopies (Smart et al., 1985) (Cortell et al., 2007).

Grapevines of high vigor are generally characterized by having relatively larger leaves and higher shoot densities creating additional shade in the canopy (Smart, 1985) (Smart et al., 1985). Of all things that negatively affect phenolic accumulation in grapes and subsequent wine quality, excessive vigor is the most damaging (Downey et al., 2006). Generally, high vigor grapevines yield fruit with decreased soluble solids, anthocyanins and tannin while berry size, TA and must nitrogen levels are generally increased (Cortell et al., 2007) (Cortell et al., 2008). Canopy division, Smart-Dyson for example, can effectively reduce vigor while maintaining or increasing yields by spreading out shoots over a greater area (Smart, 1985).

\section{Berry Development and Ripening}

Grape berries show a double sigmoid developmental pattern separated by a flat period known as lag phase (Figure 1). 


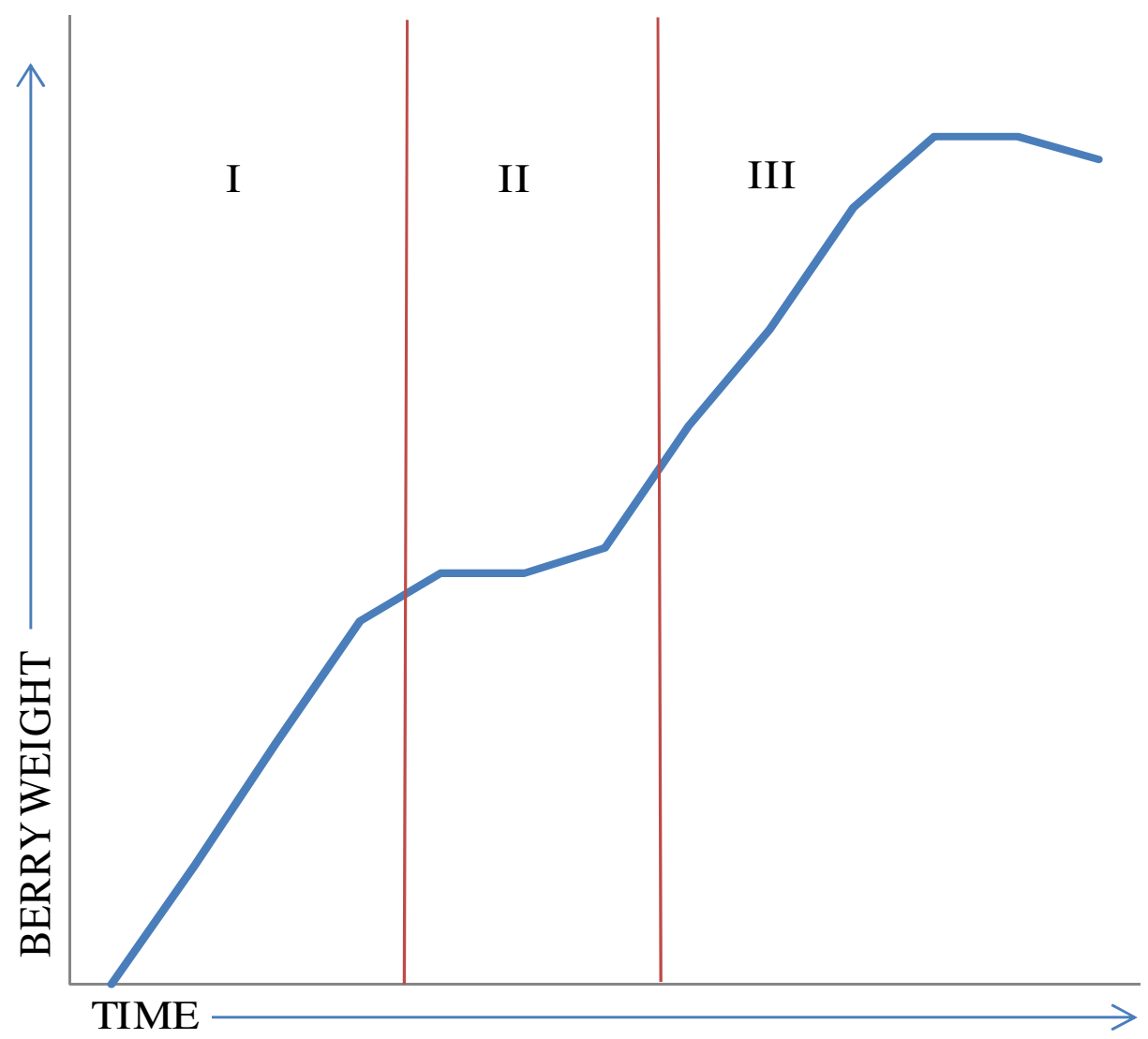

Figure 1. Diagram of a double sigmoid berry growth curve showing phases I, II and III. Adapted from Thomas et al. (2008).

After fertilization, phase I of berry growth begins and tartaric and malic acid begin to accumulate rapidly in the berry's vacuole, berries also go through rapid growth by limited cell enlargement and rapid cell division at this time (Pratelli et al. 2002). Berry growth slows during phase II and organic acids reach their potential just before the end of phase II (Pratelli et al. 2002). The start of ripening, known as veraison, coincides with the start of berry softening and color accumulation (Boss et al., 1996) (Pratelli et al. 2002). Sugars increase rapidly following veraison while acid content starts to decrease, in part due to malic acid being converted to sugar (Dokoozlian and Kliewer, 1996) (Pratelli et al. 2002). After veraison, the berry depends on cell enlargement rather than cell division for growth (Pratelli et al. 2002). 
As grape berries reach the end of phase III of the berry growth curve, they lose weight and can have a shriveled appearance, as seen with certain cultivars such as shiraz, the total weight loss can reach $30 \%$ and begin long before the fruit is ready to be harvested (Rogiers et al., 2004). Up to $90 \%$ of berry weight loss can be attributed to water vapor (Rogiers et al., 2000). Rogiers et al. (2004) reported that after reaching a maximum average weight 95 days after flowering of $1.5 \mathrm{~g} /$ berry, shiraz berry weights declined to $1.2 \mathrm{~g} /$ berry 20 days later. This weight loss represented $20 \%$ of the individual berry weight. Boss et al. (1996) found that berry volume increased to a maximum of $1183 \mathrm{~mm}^{3}$ three weeks before harvest and then decreased to $756 \mathrm{~mm}^{3}$ at commercial harvest. If the amount of water entering the berry through the pedicel is not able to keep up with the amount lost through the cuticle in the way of vapor then shriveling will occur (Boss et al., 1996).

Enzymes play an important role in the softening of berries by de-polymerizing polysaccharides responsible for their original rigidity (Nunan et al., 1998). Enzymatic reactions increase during and after veraison and the related softening of berries that occurs is marked by changes in the cell walls, which are made up of in part, proteins and phenolic compounds (Ortega-Regules et al., 2008). A study that investigated berry cell wall composition found that the harder the structure of an individual berry, based on its quantity of cell wall material, the lower the amount of sugars present (Ortega-Regules et al., 2008). They reported a correlation between ripeness based on soluble solids, and a decrease in cell wall material, $\mathrm{R}^{2}=76.95 \%$. The quantity of cell wall material in berries at harvest was found to be the lowest in syrah in the same study comparing it to monastrell, cabernet sauvignon and merlot perhaps indicating an inherent nature of syrah to increased softening compared to other cultivars of Vitis vinifera. 


\section{Pruning Severity and Timing}

The severity of winter pruning is one of the components that most affects eventual vine size and subsequent degrees of shade in the canopy (Smart et al., 1985). Pruning severity has a direct effect on yield and yield parameters by pre-determining initial shoot numbers, cluster sizes and number of clusters (Smart et al., 1982) and it is indirectly responsible for changes in berry chemistry due to changes in yield. Depending on the pruning severity, much of the stored carbohydrates in dormant wood can be removed and in the process slow early season shoot development. Severely pruned vines develop less individual leaves on a whole vine basis than non-severely pruned vines, but leaf numbers per shoot and individual leaf sizes increase (Smart et al., 1982).

Light pruning will generally increase yield but only to a certain point where the vine becomes too large and fruitfulness eventually decreases (Smart et al., 1982). Individual cluster weight is most often increased through severe pruning but the effect of overall yield loss through fewer clusters per vine can't be made up for completely by a greater yield/cluster (Bowed and Kliewer, 1990). Byrne and Howell (1978) tested different pruning levels and found that as severity of pruning increased from 50+10 to $10+10$ (\# of buds retained/vine for first pound of prunings + \# of buds retained/vine for each additional pound of prunings), yield decreased from $7.0 \mathrm{~kg} /$ vine to $3.6 \mathrm{~kg} / \mathrm{vine}$.

Increasing yield through reduced pruning severity does not necessarily reduce fruit quality because it usually results in a reduced berry size beneficial to vinification (Freeman, 1983). Increasing the total amount of buds retained at winter pruning increased quality in terms of color density and anthocyanins and was most likely due to decreased cluster and berry size 
(Freeman, 1983). Byrne and Howell (1978) found that total color was increased at the most severe pruning level, however, the tasting panel gave wines made from severely pruned vines lower scores than wines made from vines less severely pruned.

The effect of pruning severity on yield parameters is not always consistent from year to year as shown in a four year study conducted by Freeman et al. (1979). The number of clusters/shoot was significantly affected in some years and not affected in others. For example, in year 1 of the study, clusters/shoot increased $25 \%$ when the amount of buds left during winter pruning doubled from 20 to 40 . In the same year when bud numbers were doubled again to 80, clusters/shoot was not significantly affected. Bud numbers were doubled again in the same year to 160 per vine and the number of clusters/shoot increased significantly $29 \%$. In years 2 and 4 of the study, pruning level did not affect the number of clusters/shoot significantly (Freeman et al., 1979). In a related study clusters/vine nearly doubled when severity of pruning decreased from 10+10 to 50+10 increasing from 67/vine to 112/vine (Byrne and Howell, 1978). They found that as pruning severity increased, overall vine size was reduced. There is not always a change in pruning weights due to the changing pruning level; however, the average weight of individual canes is always affected increasing in weight as pruning severity increases (Freeman et al., 1979).

The timing of pruning can affect yield parameters (Friend and Trought 2007) as well as disease population (Weber et al., 2007). Delaying pruning until late March compared to early January, decreased overall cane lengths measured the following winter (Friend and Trought 2007). In the same study, delayed pruning resulted in an increase in yield between 63 and $93 \%$ with the greatest increase in yield coming from the treatment receiving the latest pruning. Delayed pruning also delays other physiological processes to a time when more favorable 
growing conditions occur (Friend and Trought 2007) (Weber et al., 2007). Delayed pruning has also been used as part of a double pruning regimen to reduce disease infection such as Eutypa lata (Weber et al., 2007). This study reported that infections of Eutypa lata were reduced from $65 \%$ to $7.5 \%$ when final pruning was delayed until after the rainy season.

\section{Shoot Thinning}

The effects of shoot thinning depend on the timing and severity and are generally positive on canopy microclimate and berry chemistry and are due in part to the indirect effect of fruit removal (Reynolds et al., 2005). The later in the season shoot thinning occurs the greater the reduction of vigor but the more difficult and expensive the process becomes from a labor standpoint. Regardless of the timing of shoot thinning, light penetration into the canopy will increase to varying degrees and the greatest difference will be noted in vines considered extremely vigorous (Reynolds et al., 2005).

Generally, as shoot density decreases from shoot thinning, there is a corresponding decrease in yield, clusters/vine and an increase in cluster weight, berries/cluster and berry weight (Reynolds et al., 1994b). Yield per vine was significantly reduced when shoot thinning was applied decreasing from $6.0 \mathrm{~kg} / \mathrm{vine}$ at 28 shoots/vine to $2.9 \mathrm{~kg} / \mathrm{vine}$ at 12 shoots/vine (Myers et al., 2008). Shoot thinning caused a decrease in tons per hectare from $15.48 \mathrm{t} / \mathrm{ha}$ to $10.55 \mathrm{t} / \mathrm{ha}$, and a decrease in clusters/vine from 68.5 to 34.5 (Reynolds et al., 1994b). Reynolds et al. (1994a) reported that as shoot density decreased from 40 to 20 shoots/meter trellis, yield decreased on the average from 16.8 tons/ha to 14.3 tons/ha. While at the same time, average cluster and berry weights increased from $64.1 \mathrm{~g}$ to $84.7 \mathrm{~g}$ and from $1.37 \mathrm{~g}$ to $1.43 \mathrm{~g}$ respectively. 
Pruning weights are not always significantly affected by the differing number of shoots imposed on a vine through shoot thinning (Myers et al., 2008) because grapevines are able to direct vigor to fewer shoots and increase individual cane weight (Naor et al., 2002). Pruning weights were not significantly different in another experiment due to three different shoot densities: 20, 30 and 40 shoots per meter trellis (Reynolds et al., 1994a). In another study, pruning weights were not significantly different due to different shoot densities in the first and second year, however, in the third year, vines that were shoot thinned increased in pruning weights from $1.8 \mathrm{~kg} /$ vine to $2.2 \mathrm{~kg} /$ vine (Naor, et al., 2002). In a related study, pruning weights decreased slightly but not significantly from $.75 \mathrm{~kg} / \mathrm{vine}$ at 12 shoots/vine to $.71 \mathrm{~kg} / \mathrm{vine}$ at 28 shoots/vine (Myers et al., 2008).

The Ravaz index is a fruit to pruning weight ratio that viticulturists use to determine vine balance which influences the pruning process. A vineyard can't sustain production with a Ravaz index over 10, while the target for high quality grapes is from 3 to 7 . Ravaz index values generally decrease with shoot thinning (Naor et al., 2002) (Myers et al., 2008) (Reynolds et al., 1994b). Naor et al. (2002) found that in all three years of their shoot density experiment, Ravaz index values decreased when shoot thinning was conducted from 5.4 to $2.4,7.1$ to 2.4 and 7.6 to 3.1 respectively. Myers et al. (2008) found that Ravaz index values were reduced significantly from 8.4 to 3.9 when shoot thinning was conducted. Reynolds et al. (1994b) reported that shoot thinning caused a decrease in Ravaz index values from 16.28 to 9.25 which was an over-cropped vineyard before shoot thinning was applied.

Shoot thinning increases cluster and leaf exposure and has been shown to indirectly increase soluble solids through fruit removal (Reynolds et al., 2005). Shoot thinning also increased total anthocyanins (Reynolds et al., 1996) and decreased must pH (Reynolds et al., 
2005) (Reynolds et al., 1996). After shoot thinning was applied to vines to create different shoot densities; an increase in average shoot length was observed from $.9 \mathrm{~m}$ at 28 shoots/vine to $1.4 \mathrm{~m}$ at 12 shoots/vine (Myers et al., 2008). The leaf area per vine was not significantly affected by shoot thinning, as it decreased only slightly from $5.0 \mathrm{~m}^{2}$ at 28 shoots/vine to $4.7 \mathrm{~m}^{2}$ at 12 shoots/vine. However, the average leaf area per shoot increased significantly from $.17 \mathrm{~m}^{2}$ at 28 shoots/vine to $.33 \mathrm{~m}^{2}$ at 12 shoots/vine (Myers et al., 2008). Soluble solids of juice increased linearly when shoot density was reduced by shoot thinning from $23.6^{\mathrm{O}}$ to $25.0^{\mathrm{O}}$ (Reynolds et al., 1994a).

\section{Shading and Leaf Removal}

Leaf removal in the fruit zone increases cluster exposure to light and solar radiation, therefore it is challenging to measure the individual effects of each (Dokoozlian and Kliewer, 1996) (Downey et al., 2004). The timing of leaf removal is important and can affect phenolic and sugar accumulation (Dokoozlian and Kliewer, 1996). Downey et al. (2004) reported that increased shade due to the lack of leaf removal caused a $35 \%$ decrease in berry weight compared to the exposed treatment at harvest. The same study reported that soluble solids were not significantly different due to shade. Ristic et al. (2007) found that shading within the fruit zone caused a $20 \%$ reduction in berry size. However, a contradictory study reported berry weights increased from $2.03 \mathrm{~g} /$ berry in exposed fruit to $2.12 \mathrm{~g} /$ berry in shaded fruit (Pereira et al., 2006).

In a study that compared degrees of vine shading with degrees of individual bunch shading, $90 \%$ vine shading reduced berry weights while $90 \%$ bunch shading increased berry weights (Bureau et al., 2000). For example, 90\% vine shading had an average berry weight of $.84 \mathrm{~g} /$ berry while the treatment with full sun exposure had an average berry weight of 1.65 
g/berry (Bureau et al., 2000). However, when only the bunches were shaded at $90 \%$, berry weights increased slightly from 1.65 to $1.70 \mathrm{~g} /$ berry with full sun exposure (Bureau et al., 2000).

Dokoozlian and Kliewer (1996) tested the effects of timing of leaf removal and observed a decrease in berry size and a delay in ripening parameters when leaf removal was delayed until phase III of berry growth. For example, 26 days after berry set, only $6 \%$ of total berries had softened and $0 \%$ had accumulated color in treatments where leaf removal had note been completed, as opposed to $25 \%$ of total berries softened and $18 \%$ of berries accumulated color in treatments where leaf removal was completed immediately after berry set. Similar berry weight and diameter were found with treatments where leaf removal was delayed until phase III or not completed at all during the experiment. When no leaf removal was completed during the growing season, the lowest amount of total phenolics was recorded (Dokoozlian and Kliewer, 1996). In a related study, leaf removal in the fruit zone during veraison showed no significant effect on clusters/vine; yield/vine or on individual cluster weight but did increase soluble solids (Bavaresco et al., 2008).

Early leaf removal before flowering is complete can lead to a reduced fruit set and less tight clusters (Poni et al., 2006). We also see an increase in soluble solids, color of must, total phenolics and titrable acidity, which was attributed to a reduced berry size (Poni et al., 2006). When working with a cultivar that has a tendency to over-crop or set tight clusters, a poor fruit set due to early leaf removal could reduce the amount of crop thinning needed later in the season and reduce the chance of pathogen infection (Poni et al., 2006).

Generally, berries grown in full sun compared to partial sun, have decreased organic acids and total acidity but increased soluble solids and nitrogen in the amino acid form (Pereira 
et al., 2006) (Ristic et al., 2007) (Cortell and Kennedy, 2006). A decreased berry size is usually responsible for the increased concentration of sugars and amino acids (nitrogen), while the decrease in organic acids and total acidity is related to the increased internal temperature of exposed berries (Pereira et al., 2006). The sum of organic acids decreased from 138.9 meq./L $\mathrm{L}^{-1}$ in the shaded fruit to 125.3 meq. $/ \mathrm{L}^{-1}$ in the exposed fruit (Pereira et al., 2006). In the same study, total acidity decreased from 101 meq. $/ \mathrm{L}^{-1}$ in the shaded fruit to $87.8 \mathrm{meq} . / \mathrm{L}^{-1}$ in the exposed fruit. Both must pH and TA are generally increased due to shade (Ristic et al., 2007) (Cortell and Kennedy, 2006). Contrary to the above findings, a related study found that leaf removal did not affect with statistical significance pH or TA (Bavaresco et al., 2008).

The sugar to acid ratio, a maturity index that is equal to sugar $\left(\mathrm{g} / \mathrm{L}^{-1}\right) /$ total acidity $\left(\mathrm{me} / \mathrm{L}^{-1}\right)$, is increased with sun exposure (Iacono et al., 1995) (Bureau et al., 2000). Grapes from a vine shading treatment had a sugar to acid ratio of 1.30 while the full vine exposure treatment had a sugar to acid ratio of 4.15 (Bureau et al., 2000). However, grapes subjected to cluster only shading had a sugar to acid ratio of 2.82 (Bureau et al., 2000). In a related study, sugar concentration of musts decreased from $19.8^{\circ}$ Brix in exposed fruit to $19.2^{\mathrm{O}}$ Brix in shaded fruit decreasing the sugar to acid ratio (Pereira et al., 2006). In another study, shaded treatments reduced the sugar content of the berry from $182.2 \mathrm{~g} / \mathrm{L}$ to $172.7 \mathrm{~g} / \mathrm{L}$ (Iacono et al., 1995).

Generally, berries going through veraison have $8 \%$ protein content in their cell walls which increases to $12 \%$ three weeks before harvest (Nunan et al., 1998). Nitrogen content of whole berries has been estimated to be comprised of $63 \%$ protein, $20 \%$ peptides and $17 \%$ free amino acids at harvest (Yokotsuka and Fukui, 2002). The amount of nitrogen in berries expressed in parts per million (ppm), decreased from $614 \mathrm{ppm}$ in exposed fruit to $541 \mathrm{ppm}$ in shaded fruit (Pereira et al., 2006). 
The concentration of the ammonium form of nitrogen in berries steadily decreased from veraison to harvest while the percentage of nitrogen in the amino acid form steadily increased from veraison to harvest (Garde-Cerdon et al., 2009). Grapes with the highest total nitrogenous compounds also had the highest sugar to acid ratio (Garde-Cerdon et al., 2009). Grapes with the highest sugar to acid ratio also had the highest color density (Garde-Cerdon et al., 2009). The combination of low light levels in the canopy and high availability of nitrogen caused total pigments to be greatly reduced at harvest (Keller and Hrazdina, 1998).

Potassium is the most prevalent cation in the grape berry and $40 \%$ of the overall potassium found in berries is located in the skin (Pratelli et al. 2002) (Iland and Coombe, 1988). Potassium has a high degree of mobility in plants and plays a role in protein synthesis, photosynthesis, stomatal movement, phloem transport and plant growth (Marschner, 1995). A potassium deficiency in grapevines is often linked with a decrease in soluble solids, phenolics and amino acid accumulation in the berry (Brancadora et al., 1994). When potassium is sufficient, the efficiency of photosynthates transferred from source to sink via the phloem increases due to the influence that potassium has on the osmotic potential in the sieve tube elements (Marschner, 1995). Potassium concentration in berries is dependent on its availability in the soil and management practices that affect the degree of shade (Davies et al., 2006) (Brancadora et al., 1994) (Smart et al., 1985). The concentration of berry potassium is at its peak when berries are around one week old then decreases to a minimum between 5 and 7 weeks postflowering then increases steadily again until harvest (Davies et al., 2006).

Potassium concentration in berries on the average across all treatments (shaded and nonshaded) was $2.36 \mathrm{mg} / \mathrm{ml}$ at veraison and had increased to $2.71 \mathrm{mg} / \mathrm{ml}$ at commercial harvest (Smart et al., 1985). Potassium content in berries, expressed in percentage dry weight (\%) 
increased with shade although not significantly in one experiment from $.92 \%$ to $.94 \%$ (Iacono et al., 1995). The amount of potassium in leaves, stems and petioles increased from flowering to veraison and then had decreased by commercial harvest (Smart et al., 1985). The percentage potassium in leaves and petioles across all treatments decreased on average from $1.38 \%$ to $.81 \%$ from veraison to harvest (Smart et al., 1985). The percentage potassium in rachises across all treatments, decreased on average from $2.38 \%$ to $2.13 \%$ from veraison to harvest and shade treatments had the highest value at veraison in the following plant parts: rachis, fruit, leaves, petioles and stems (Smart et al., 1985).

\section{Phenolics}

Total phenolic content of grapes is a good indicator of light exposure on fruit because it is known that their initial synthesis is triggered by light and secondarily by temperature (Pereira et al., 2006). Based on their structure, phenolics can be broken down into two main groups, flavonoids and non-flavonoids (Cheynier et al., 2006). Flavonoids, also known as flavanols or proanthocyanidins, include anthocyanins and condensed tannins. Condensed tannins are the largest class of phenolics in the berry, followed by anthocyanins (Harbertson et al., 2003). Astringency in grapes due to tannin presence contributes to sensory qualities in wine that increase quality (Cortell et al., 2008). Astringency of grapes is greatly reduced between veraison and harvest, conversely, sugar and anthocyanin accumulation increases dramatically during this time period (Downey et al., 2006). This gives the plant a better chance to disperse its seed because as the seed is becoming ripe, the berry itself will seem more attractive to seed dispersal mechanisms (Downey et al., 2006). 
Generally, flavonoids have two different periods of initial synthesis, one that take place at flowering and one around veraison (Downey et al., 2006) (Boss et al., 1996). Anthocyanins are not measurable until veraison while condensed tannins are measurable in berries after set (Boss et al., 1996). Cold soaking, or pre-fermentation skin contact with juice at low temperatures increases skin derived tannin and anthocyanin, while extended contact of skin and seeds with wine increase tannin derived from seed (Cheynier et al., 2006).

The phenolics present in grapes are correlated with the final phenolic makeup of wine. Skin tannins measured in grapes are well correlated with wine astringency, $\mathrm{R}^{2}=.784$ (Cortell et al., 2008). Jensen et al. (2008) found that in syrah grapes, on average $47 \%$ of the anthocyanins were recovered in the final wine product that were present in must. This was $5 \%$ higher than the average recovered from all Vitis vinifera cultivars tested including: alicante, cabernet sauvignon, carignan, cinsault, grenache, syrah, merlot and mourvedre. Total tannin content recovered from syrah grapes in the final wine product were only $25 \%$ of the total in pre-fermentation must. This was $7 \%$ lower than the average for all cultivars tested. Total phenolics recovered in the final wine product were $43 \%$ of the total present in the must; which was $1 \%$ lower than the average of all cultivars tested. Over all cultivars, wine anthocyanins were well correlated with grape anthocyanins, $\mathrm{R}^{2}=.94$, and phenolics, $\mathrm{R}^{2}=.83$. Total wine color was also well correlated with grape anthocyanins, after $\mathrm{pH}$ adjustment $\mathrm{R}^{2}=.83$. Red wine color is dependent on the level of anthocyanins, $\mathrm{pH}$ and the level of other compounds that polymerize with anthocyanins (Jensen et al., 2008). 


\section{Anthocyanins}

Anthocyanins are generally located in the hypodermis portion of the skin of red grape cultivars, with the exception of teinturier varieties whose anthocyanins are located throughout the berry (Cheynier et al., 2006) (Harbertson et al., 2003). Anthocyanin concentration generally peaks around 1 to 2 weeks before harvest and then slightly decreases by the time most berries reach their optimum ripeness based on sugar concentration (Roggero et al., 1986). Even though grapes start to accumulate color during phase III of berry growth, it is necessary for fruit to be exposed to light during phases I and II for the biosynthesis to initiate (Dokoozlian and Kliewer, 1996). Furthermore, berries need light exposure after the start of veraison so that light dependent enzymatic reactions responsible for further color accumulation reach their potential (Dokoozlian and Kliewer, 1996). Additionally, after shading treatments are applied and then removed, flavonol accumulation is halted and does not resume, indicating a strong relationship between the initial flavonol biosynthesis and light exposure (Downey et al., 2004).

The evolution of individual anthocyanins over the course of ripening can help in the understanding of biosynthetic pathway (Roggero et al., 1986). Multiple studies have found that total anthocyanins increase or decrease with increasing canopy shade without consistency (Downey et al., 2004) (Ristic et al., 2007). However, when broken down into individual anthocyanin concentration, a distinction is evident. Cyanidin and peonidin based anthocyanins belong to a di-oxygenated group who's percentage of total anthocyanins significantly increased with shade (Downey et al., 2004) (Ristic et al., 2007). Delphinidin, petunidin and malvidin belong to the tri-oxygenated group which represents the majority of total anthocyanins in shiraz, and their percentage of total anthocyanins significantly decreased with shade (Downey et al., 2004) (Ristic et al., 2007). Roggero et al. (1986) tested pigment concentrations in response to 
shade and found that delphindin which was stable ranging from 12-16\% of total anthocyanins, dropped significantly in response to canopy shade.

The general upward trend in global temperatures will most likely affect the color accumulation of grapes. Mori et al. (2005) reported that high night time temperatures tend to decrease anthocyanin accumulation as opposed to low night time temperatures which have the tendency to increase anthocyanin accumulation. For example, $30^{\circ} \mathrm{C}$ day time temperature combined with $30^{\circ} \mathrm{C}$ night time temperature versus $30^{\circ} \mathrm{C}$ day time temperature combined with $15^{\mathrm{O}}$ night time temperature caused anthocyanins to decrease from $5.5 \mathrm{mg} / \mathrm{g}^{-1}$ to $4.0 \mathrm{mg} / \mathrm{g}^{-1} \mathrm{flesh}$ weight of skin. There was not an effect of night time temperatures on other flavonol accumulation in skins or on soluble solids of berry. Generally, with higher temperatures berry growth speeds up and the biosynthesis of anthocyanins decreases (Mori et al., 2005).

\section{Tannin}

Most seed and skin tannins are found in the proanthocyanidin form (Cheynier et al., 2006). The major terminal subunit in shiraz skin is catechin which ranges between $69 \%$ and $83 \%$ of all terminal subunits (Hanlin and Downey, 2009). Skin tannins can be differentiated from seed tannin by their larger size or higher degree of polymerization (Cortell et al., 2008). There is a greater percentage of total tannins located in the seed, thus, grape seeds have more oxygen-radical absorbing capacity than their skins (Yilmaz and Toledo, 2004). The browning of seeds that occurs during the end of phase III of berry growth can indicate a degree of ripeness and is due to oxidation of tannins not lignification (Adams, 2006). Although the seed is located inside the flesh of the fruit, it experiences water loss as it increases in brown color (Adams, 2006). 
There was no statistical difference in concentration of seed tannins over the course of the three year study conducted by Downey et al. (2004) based on shade. However, Ristic et al. (2007) found that seed tannins increased on a concentration basis in the shaded treatments, which was most likely an indirect result of an increased seed size from 20.7 to $24.6 \mathrm{mg} / \mathrm{seed}$ in the shaded fruit (Ristic et al., 2007). Downey et al. (2004) reported significant reductions in the levels of skin tannin due to shade. Ristic et al. (2007) also reported a decrease in skin tannins on a concentration basis in shaded treatments. For example, $32 \%$ of the total tannin content in the berry was derived from the skin while $47 \%$ of total tannin content was from the skin in the light exposed treatment. When total tannins are increased on a total amount per berry basis in shaded treatments, it is most likely due to a relatively larger seed size (Ristic et al., 2007).

Total tannin content has been shown to be highest at fruit set in shiraz six weeks prior to veraison and lowest eighteen weeks later at commercial harvest (Hanlin and Downey, 2009). Total tannin content of berries followed a similar trend to total anthocyanins where they increased and decreased without a clear distinction due to shade (Downey et al., 2004) (Ristic et al., 2007). However, there was a significant difference based on the composition of tannin due to shade presence. The 3',4'-OH (di-oxygenated) group of tannin that includes catechin increased with shade while the $3^{\prime}, 4^{\prime}, 5^{\prime}-\mathrm{OH}$ (tri-oxygenated) group decreased with the presence of shade (Downey et al., 2004) (Ristic et al., 2007). For example, the di-oxygenated group's mean percentage of total tannin increased from $64.79 \%$ to $77.95 \%$ with shade presence, while the tri-oxygenated group's mean percentage decreased from $35.21 \%$ to $22.05 \%$ when shade was imposed (Downey et al., 2004). 


\section{Methods and Materials}

\section{Site Description}

This experiment was conducted for two years at the Trestle Vineyard on the California State Polytechnic University Campus, San Luis Obispo, CA $\left(35^{\mathrm{O}} 19^{\prime} \mathrm{N}\right.$ x $\left.120^{\mathrm{O}} 41^{\prime} \mathrm{W}\right)$. Vines chosen for this experiment were syrah grafted on root stock 420a, planted in a North-South orientation. The vines were six years old and had 8'X5' spacing for a total of 1089 vines per acre. Vines were unilaterally trained; spur pruned and trellised using a Smart-Dyson training system. A total of 90 vines were utilized in this study and treatments were assigned as a randomized block.

\section{Experimental Design}

A complete randomized block factorial design was used for this experiment and was designed to assess the effects of two different pruning levels and three different canopy management techniques.

\section{Management Practices}

Management practices for this experiment were conducted by the researcher except for irrigation, fertigation, weed management and tipping (hedging). The vineyard is drip irrigated and all vines were irrigated 4 times during the growing season and 1 time post-harvest. All vines received approximately 12 gallons of water per irrigation cycle. Vines were fertigated twice a year with calcium nitrate and once a year with copper sulfate. Weed management was

performed as needed throughout the growing season using a combination of glyphosate and mechanical and manual in row cultivation. A cover crop was planted in late fall of both seasons using a combination of pea, vetch and mustard. Tipping was done mechanically once a year approximately 50\% of the way through bloom on June 15, 2008 and June 21, 2009. 


\section{Treatment description}

- Treatment group 1- vines pruned to one-bud spurs and canopies that were shoot thinned with east side only leaf removal.

- Treatment group 2- vines pruned to two-bud spurs and canopies that were shoot thinned with east side only leaf removal.

- Treatment group 3-vines pruned to one-bud spurs and canopies that were not shoot thinned with east side only leaf removal.

- Treatment group 4- vines pruned to two-bud spurs and canopies that were not shoot thinned with east side only leaf removal.

- Treatment group 5- vines pruned to one-bud spurs and canopies that were not shoot thinned but with east and west side leaf removal (both sides leaf removal).

- Treatment group 6- vines pruned to two-bud spurs and canopies that were not shoot thinned but with east and west side leaf removal (both sides leaf removal).

\section{Pruning}

Pruning of all experimental vines occurred on 4/5/08 and 4/2/09. All vines had previously been pre-pruned to a length of 5 " or 3 to 4 buds on 1/12/08 and 1/28/09 respectively. Vines were also pre-pruned on 1/27/10 to collect pruning weights from the second growing season. Because the management practices of the vineyard included mid bloom "tipping," the pruning weight data are relative and not absolute values. All pruning cuttings collected from the pre-prune were weighed using a digital fish scale (model 16KG, Berkley, Iowa, USA). During the second pruning completed on 4/5/08 and 4/2/09, a minimal amount of stored carbohydrates in the plant were pruned off. This second pruning was completed when the top bud position started to emerge from wooly bud stage but before reaching an average of 3 inches in length. 


\section{Leaf Removal}

Fruit zone leaf removal was completed manually and at two different time periods during the growing season depending on the treatment. East side leaf removal, which was completed on all experimental vines, was completed within one week of $50 \%$ berry set. West side leaf removal was completed on treatments 5 and 6 approximately six weeks before harvest was to occur on $8 / 27 / 08$ and 8/25/09 respectively. All leaf removal was completed to the same degree no matter

if it was completed on one or both sides of the canopy and by removing the leaf only, leaving the petiole to fall off of the shoot naturally.

\section{Shoot Thinning}

Shoot thinning of treatments 1 and 2 was conducted when shoots reached an average of 18 " to 24 " in length. The dates of shoot thinning were 5/13/08 and 5/11/09 respectively. Vines were thinned to 24 shoots per meter trellis as recommended by Smart and Robinson (1992). Treatments 3, 4, 5 and 6 were not shoot thinned.

\section{Repeated Measures}

Each week, a twenty berry sample was collected from each repetition. Berries were selected from throughout the vine randomly between 9 a.m. to 12 p.m. for six weeks. Picked berries were placed in a plastic bag and directly placed into a travel cooler until they could be stored for processing in a $40^{\circ} \mathrm{F}$ refrigerator in the Post-Harvest laboratory at California State Polytechnic University, San Luis Obispo, CA.

Each week the samples were taken out of the refrigerator and subsequently processed in sets of ten. This was done to ensure that samples were processed at a similar temperature throughout the process. Processing of berries was initiated by taking them out of their bags and weighing them in a food grade plastic receptacle utilizing a digital scale (model P-2002, Denver 
Instruments, New York, USA). The weighing receptacle was dried with a paper towel between each repetition in order to avoid cross contamination. Once weighed, the berries were hand crushed and homogenized in a plastic bag and allowed to settle for 30 minutes at room temperature. The juice was then filtered into a $50 \mathrm{ml}$ beaker (Brown, personal communication).

The juice samples were allowed to settle for an additional 30 minutes and then soluble solids were determined utilizing an Abbe bench top refractometer (model LR 45-227, Milton Roy, New York, USA). The $\mathrm{pH}$ of each sample was then determined with a Dual Channel $\mathrm{pH}$ meter with an electrode with a temperature compensating probe (model AR50, Fisher Scientific, Illinois, USA) (Brown, personal communication). Titratable acidity (TA) was determined according to protocol described by Zoeklin (1995) using a method by which a diluted form of each juice sample was titrated by sodium hydroxide (.1333 N NaOH).

\section{Vineyard Scoring}

Vineyard scoring using the Point Quadrant System as described by Smart and Robinson (1992), determined the different leaf layer number, percentage of gaps, percent interior leaves and percent interior clusters. Ten measurements per repetition were used instead of the 60 recommended by Smart and Robinson (1992) because of the limited labor available for this research. These ten measurements were taken every 10 centimeters in the fruit zone of the canopy using a $1 / 8^{\text {th }}$ inch diameter stick. Each insertion was done in the fruit zone above the cordon only. Ten data points from each repetition were combined into treatment groups to show general trends using a histogram.

\section{Harvest Description}

At harvest, fruit from each experimental unit was harvested separately into 10 gallon food grade plastic bins. All experimental units were transferred from the vineyard site to the Crops 
Unit Laboratory at California State Polytechnic University, San Luis Obispo, CA. All experimental units were then sorted and weighed using a digital scale (model CD-11, Ohaus, New Jersey, USA).

In 2008, after being weighed individually, the repetitions were combined into treatments to show general trends. In 2009, the following yield parameters for each repetition were taken: weight, berries/cluster, rachis weight, and clusters/cane. In 2009, 12 clusters chosen at random from each repetition were kept separate for post-harvest analysis conducted at Baker Wine and Grape Analysis in Paso Robles, CA. The clusters were de-stemmed and placed into plastic freezer bags then placed in a freezer with the temperature of $-70^{0} \mathrm{C}$ in the Post-Harvest Laboratory.

\section{Laboratory Analysis}

Approximately two weeks after harvest in 2009, the de-stemmed berries were transferred to Baker Wine and Grape Analysis in Paso Robles, CA. All samples were placed in a residential freezer and taken out in sets of ten to de-thaw the night before analysis in a residential refrigerator set at $40^{0} \mathrm{~F}$.

From the de-stemmed berries, 250 grams were selected at random, weighed with a digital scale (model DSI 2001, Acculab, New York, USA), then left to acclimate to room temperature for 30 minutes and then homogenized in a plastic bag. The juice from the homogenized berries was then poured through a metal filter from a bag which was slightly squeezed so that no liquid remained. This juice was allowed to settle at room temperature for 30 minutes before measuring the following performance indicators: soluble solids, titratable acidity, potassium, malic acid, tartaric acid, and nitrogen composition using a FTIR interferometer Wine Scan ${ }^{\mathrm{TM}}$ (model FT 120, 
FOSS, Denmark). The $\mathrm{pH}$ of each sample was determined manually utilizing a

pH/temp./MV/ISE meter (model 390, Beckman Coulter, Delaware, USA). Sample analysis was completed in sets of ten and done within the span of one day so that no re-freezing of samples was needed. All analysis of performance indicators determined by the FTIR interferometer Wine $\mathrm{Scan}^{\mathrm{TM}}$ (model FT 120, FOSS, Denmark), were run in duplicates or triplicate with the average reported and used for statistical analysis.

An additional 250 grams of de-stemmed berries were selected at random, weighed using a digital scale (model DSI 2001, Acculab, New York, USA) and placed in a 1-liter square shaped food-grade plastic container. The heating of plastic containers in a microwave can cause the release of toxic chemicals which can represent over $20 \%$ of the total original weight of the container (Dixon-Anderson et al., 1988). As the duration of heating increases, so does the amount of the toxic chemicals released (Bishop and Dye, 1982). Berries were then counted to determine an average berry weight/repetition. The berries were then crushed by hand while wearing a latex glove inside the plastic box. A lid was then placed on box and was placed into a residential microwave for exactly 1 minute 20 seconds, the time required to bring the must to a slight boil. The plastic box was then taken out of the microwave and left to acclimate to room temperature for approximately 2 hours. Once cooled, the juice from the boxes was allowed to "free run" through a metal filter into a $100 \mathrm{ml}$ beaker. This juice was measured in a graduated cylinder and separated into $2-50 \mathrm{ml}$ plastic tubes. The $\mathrm{pH}$ of this juice was then adjusted by adding drops of concentrated sodium hydroxide or hydrochloric acid until it reached a $\mathrm{pH}$ between 3.58 and 3.62. The $\mathrm{pH}$ adjusted juice from the slightly boiled must was then rough filtered using a $.25 \mathrm{~mm}$ syringe filter (Fisher Scientific, Illinois, USA) producing approximately $20 \mathrm{ml}$ of liquid. A second, fine filtration of the $20 \mathrm{ml}$ through a $.45 \mathrm{~mm}$ syringe filter (Fisher 
Scientific, Illinois, USA) produced approximately $10 \mathrm{ml}$ of extract used for measurements. Each syringe was rinsed and dried between each repetition and a new filter was used for each repetition for both filtration processes (Baker, personal communication).

The extract was used to measure total phenolics, color density, color hue, total anthocyanins, and total tannins utilizing a U.V. /VIS. Spectrophotometer (model DU 530, Beckman Coulter, Delaware, USA). Total phenolics, color density and hue were measured after diluting $1 \mathrm{ml}$ of extract into $99 \mathrm{ml}$ of de-ionized water with values reported in equivalent units as no standard was available to create a standard curve to determine concentration. Total phenolics were measured at $280 \mathrm{~nm}$ wavelength and recorded by multiplying the absorbance by a factor of 100. Color density was measured by adding the absorbance at $420 \mathrm{~nm}$ wavelength with the absorbance at $520 \mathrm{~nm}$ wavelength and multiplied by a factor of 10 . Color hue was measured by dividing the absorbance at 420nm with 520nm and multiplying by a factor of 10 (Baker, personal communication).

Total anthocyanins were measured after adding $10 \mathrm{ml}$ of anthocyanin buffer to $1 \mathrm{ml}$ of extract. The anthocyanin buffer used was potassium chloride mixed with hydrochloric acid and was used to lower the $\mathrm{pH}$ of the extract as close to 1 as possible to accentuate the color of the solution before measurement. Total anthocyanins were measured at 520nm wavelength and recorded after multiplying the absorbance by a factor of ten. This number was applied to a standard curve that was created using a malvidin standard to arrive at a parts per million (Appendix 4). Total tannin content estimated in catechin equivalents, was determined using the Adams Harbertson Tannin Assay (Appendix 1) but instead of finished wine, the sample measured was the same extract used for measuring anthocyanins. Total tannin content in catechin equivalents was applied to a standard curve (Appendix 2) that was created using a 
catechin standard to arrive at parts per million and were recorded as part of a ratio with total anthocyanins.

\section{Statistical Analysis}

The following diagnostics for general linear models as set forth by Steinmaus (2007) were made before any analysis of statistics was conducted: physiological independence of experimental units and normally distributed data. Physiological independence was assured through the randomization of the repetitions before the experiment began and through the use of buffer vines. Normality of data was tested for using a series of numerical normality tests and a univariate normality plot data. Differences between treatments were subjected to Tukey's means separation procedure.

All data accumulated during 2008 and 2009 was entered into EXCEL spreadsheets (model Student 2007, Microsoft, Washington, USA) for storage and analyzed using a Regression Model, Analysis of Variance (ANOVA) or a Univariate Repeated Measures Analysis of Variance (MANOVA) with SAS statistical software (SAS-Institute, North Carolina, USA). 


\section{$\underline{\text { Results and Discussion }}$}

\section{Phenology Stages}

Phenology dates for both growing seasons were similar (Table 1). In 2008, harvest date was selected after an average from all experimental units was met for each performance indicator. In 2009, harvest date was selected in the same way but was adjusted to a slightly earlier date when heavy rains were forecasted. Phenology dates were recorded when it was determined that they were 50\% complete (Mayr, 1985).

Table 1. Phenology dates for syrah grapevine at Trestle Vineyard, California State Polytechnic University, San Luis Obispo, CA.

\begin{tabular}{cccccc}
\hline Season & Bud-burst (50\%) & Bloom (50\%) & Berry set (50\%) & Veraison (50\%) & Harvest \\
\hline 2008 & $3 / 30$ & $6 / 15$ & $6 / 21$ & $8 / 11$ & $10 / 9$ \\
2009 & $4 / 1$ & $6 / 12$ & $6 / 17$ & $8 / 14$ & $10 / 7$ \\
\hline
\end{tabular}

\section{Management Practices}

Management practices were in large part dependent on the above listed phenology dates.

Pre-pruning was conducted on all experimental units when all leaves had fallen which in 2009 was very late into dormancy (Table 2).

Table 2. Management practices dates for syrah grapevine at Trestle Vineyard, California State Polytechnic University, San Luis Obispo, CA.

\begin{tabular}{cccccc}
\hline Season & Pre-Pruning & Spring Pruning & East Leaf Removal & Shoot Remova* & West Leaf Removal** \\
\hline 2008 & $1 / 12$ & $4 / 5$ & $6 / 14$ & $5 / 13$ & $8 / 27$ \\
2009 & $1 / 28$ & $4 / 2$ & $6 / 21$ & $5 / 11$ & $8 / 25$ \\
\hline
\end{tabular}

* Shoot removal only conducted on treatments 1 and 2. ** West side leaf removal only conducted on treatments 5 and 6. 


\section{Repeated Measures Analysis}

To test the response of berries to seasonal and treatment differences in 2008, we measured brix, TA, pH and weight for six weeks leading up to harvest. In 2008 there were no significant differences between treatments indicating that fruit from all experimental vines matured at a similar rate (Table 3). These results were expected based on year 1 pruning data in experiments completed by Byrne and Howell (1978) and Freeman et al. (1979) that found that Vitis vinifera has great ability to compensate in the short term, temporarily overcoming the effects of severe pruning and other canopy management practices.

Table 3. Effect of pruning and canopy treatment on berry maturation rates in 2008 of syrah grapevine at Trestle Vineyard, California State Polytechnic University, San Luis Obispo, CA. ${ }^{\mathrm{a}}$

\begin{tabular}{rccccc}
\hline & Weight (grams) & Brix (degrees) & TA (g. tart/100 ml) & $\mathrm{pH}$ & Sugar to Acid Ratio \\
\hline Pruning Treatment & & & & & \\
Severe & $28.19 \mathrm{a}$ & $24.43 \mathrm{a}$ & $0.51 \mathrm{a}$ & $3.49 \mathrm{a}$ & $4.78 \mathrm{a}$ \\
Standard & $28.97 \mathrm{a}$ & $24.96 \mathrm{a}$ & $0.53 \mathrm{a}$ & $3.49 \mathrm{a}$ & $4.72 \mathrm{a}$ \\
Significance & $n s$ & $n s$ & $n s$ & $n s$ & $n s$ \\
& & & & & \\
Canopy Treatment & & & & & \\
Standard & $27.77 \mathrm{a}$ & $24.69 \mathrm{a}$ & $0.52 \mathrm{a}$ & $3.46 \mathrm{a}$ & $4.77 \mathrm{a}$ \\
No Shoot Thinning & $27.77 \mathrm{a}$ & $25.00 \mathrm{a}$ & $0.51 \mathrm{a}$ & $3.54 \mathrm{a}$ & $4.89 \mathrm{a}$ \\
Both Sides Leaf Removal & $30.24 \mathrm{a}$ & $24.39 \mathrm{a}$ & $0.53 \mathrm{a}$ & $3.48 \mathrm{a}$ & $4.59 \mathrm{a}$ \\
Significance & $n s$ & $n s$ & $n s$ & $n s$ & $n s$ \\
\hline
\end{tabular}

${ }^{\mathrm{a}}$ MANOVA indicated not significantly different if $\mathrm{p}$-value was greater than 0.05 .

\section{Harvest Parameters Analysis}

Because we did not run statistics of harvest data in 2008 except for total yield/repetition $(\mathrm{kg})$, yield $/ \mathrm{meter}$ trellis $(\mathrm{kg} / \mathrm{m})$, pruning weights $(\mathrm{kg})$ and Ravaz index, most of the harvest parameters data from 2008 shows trends based on averages from each treatment. The average cluster weight ranged from a low of 63.6 grams from treatment 4 (standard pruning, no shoot thinning, east side leaf removal) to a high of 105.2 grams from treatment 5 (severe pruning, no shoot thinning, both sides leaf removal) (Figure 2). Treatments that were subjected to severe 
pruning (1,3 and 5) had a higher average cluster weight than the non-severely pruned treatments $(2,4$ and 6) (Figure 2). Although only a trend, these results are consistent with other pruning studies that found that severe pruning increases individual cluster weight (Bowed and Kliewer, 1990).

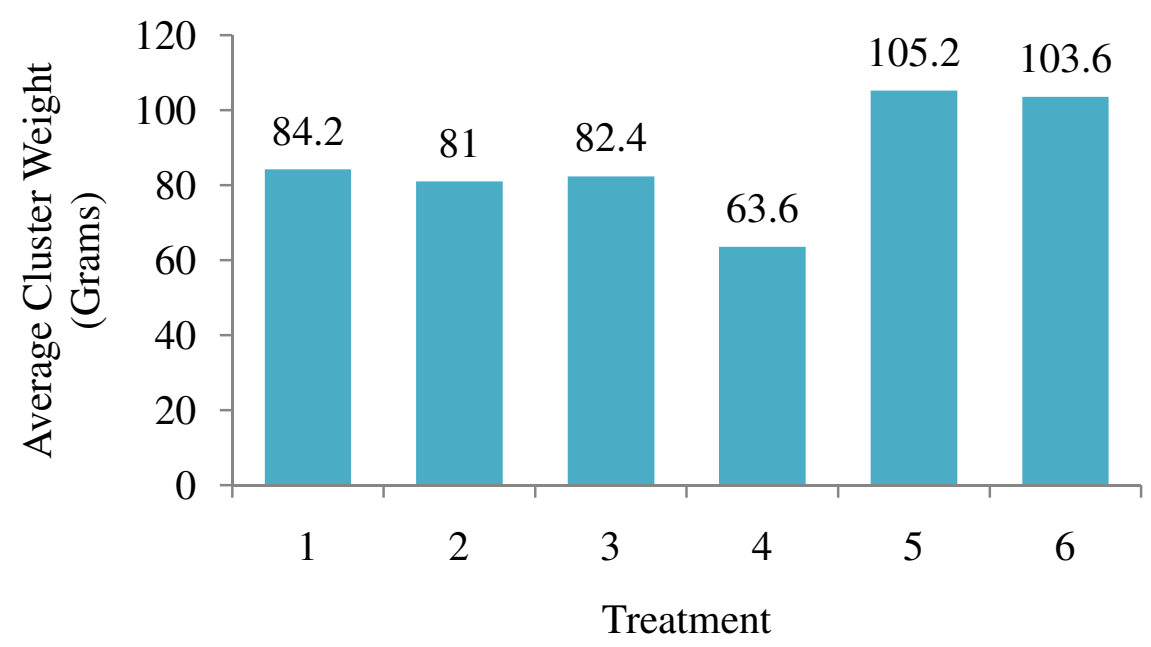

Figure 2. Effect of pruning level and canopy management practices on average cluster weight in 2008 of syrah grapevine at Trestle Vineyard, California State Polytechnic University, San Luis Obispo, CA.

The average weight of 100 berries ranged from a low of 82 grams from treatment 4 (standard pruning, no shoot thinning, east side leaf removal) to a high of 174 grams from treatment 1 (severe pruning, shoot thinning, east side leaf removal) (Figure 3). Treatments that were subjected to severe pruning (1,3 and 5) had a higher average berry weight than the nonseverely pruned treatments (2,4 and 6) (Figure 3). Although only a trend, these results are consistent with Bowed and Kliewer (1990) who reported that severe pruning increases individual berry weight. There was also an observed increase of average berry weights from treatments that were shoot thinned, which is consistent with Reynolds et al. (1994a), who reported increased berry weights in response to shoot thinning. Treatments 1 and 2 had the highest average berry weights and were the only treatments that were shoot thinned (Figure 3). 


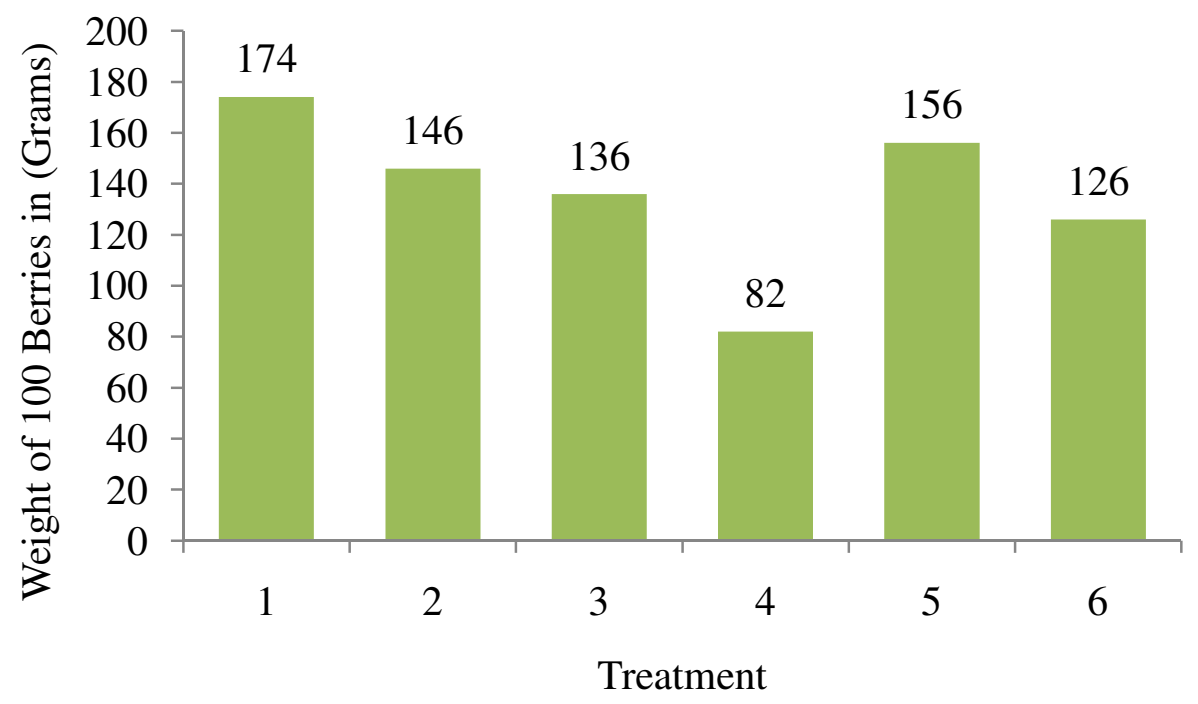

Figure 3. Effect of pruning and canopy treatment on weight of 100 berries in 2008 of syrah grapevine at Trestle Vineyard, California State Polytechnic University, San Luis Obispo, CA.

Total yield per repetition in 2008 was not significantly different due to severe pruning, shoot thinning or both sides leaf removal (Table 4). However, when yields were converted from total yield/repetition $(\mathrm{kg})$ to yield/meter trellis $(\mathrm{kg} / \mathrm{m})$ there was a significant difference due to severe pruning (Table 4). Severe pruning decreased yield/meter trellis from 1.98 to $1.18 \mathrm{~kg} / \mathrm{m}$, p>.0001. This agrees with the majority of studies involving severe pruning where a yield decrease was observed (Smart et al., 1982) (Byrne and Howell, 1978). The decrease in yield observed with severe pruning is due to the fewer clusters that are set by grapevines in response to fewer buds left during winter pruning (Bowed and Kliewer, 1990)

Ravaz index, which was calculated by dividing total yield per repetition by its pruning weight, was significantly reduced by severe pruning from 4.07 to $3.72 \mathrm{p}>.005$ (Table 4 ). In this case, severe pruning caused the Ravaz index to be lowered almost outside of optimal levels which have been previously noted (3-7). Shoot thinning and both sides leaf removal did not have a significant effect on Ravaz index in 2008 (Table 4). Our findings are not consistent with 
Naor et al. (2002) and Reynolds et al. (1994a) who found that shoot thinning tends to decrease Ravaz index values. This was expected due to this being the first year of the experiment and how Vitis vinifera is able to compensate for pruning management changes in the short term. Additionally, studies by Freeman et al. (1979) and Myers et al. (2008) found that pruning weights are not always affected by different pruning levels or different shoot densities due to the grapevines ability to redirect energy into fewer shoots.

Table 4. Effect of pruning and canopy treatment on yield parameters in 2008 of syrah grapevine at Trestle Vineyard, California State Polytechnic University, San Luis Obispo, CA. ${ }^{\text {a }}$

\begin{tabular}{rccc}
\hline & Yield/Repetition $(\mathrm{kg})$ & Yield/Meter Trellis $(\mathrm{kg} / \mathrm{m})$ & Ravaz Index** \\
\hline Pruning Treatment & & & \\
Severe & $6.11 \mathrm{a}$ & $1.65 \mathrm{a}$ & $3.72 \mathrm{a}$ \\
Standard & $7.53 \mathrm{a}$ & $1.99 \mathrm{~b}$ & $4.07 \mathrm{~b}$ \\
Significance & $*$ & $*$ & $*$ \\
& & & \\
Canopy Treatment & & & $4.05 \mathrm{a}$ \\
Standard & $6.00 \mathrm{a}$ & $1.56 \mathrm{a}$ & $3.86 \mathrm{a}$ \\
No Shoot Thinning & $6.28 \mathrm{a}$ & $1.79 \mathrm{a}$ & $3.78 \mathrm{a}$ \\
Both Sides Leaf Removal & $8.22 \mathrm{a}$ & $2.10 \mathrm{a}$ & $n s$ \\
Significance & $n s$ & $n s$ & $\mathrm{~ns}$ \\
\hline
\end{tabular}

avalues within the same column followed by the same letter are not significantly different where $\mathrm{p}=.05$, as determined by Tukey's mean separation procedure. **Ravaz index should be looked at on a relative and not an absolute basis due to the vine "tipping" conducted as a management practice.

Severe pruning increased percent bud-burst as well as individual cane weight and decreased both clusters/shoot and canes/meter trellis (Table 5). Severe pruning increased percentage percent bud-burst from 75 to $167 \%$, p>.0001, individual cane weight from 11.17 to 15.85 g. p>.0130, and decreased both clusters/shoot and canes/meter trellis from 1.62 to 1.18 , $\mathrm{p}>.0002$, and from 37.52 to $31.43, \mathrm{p}>.0007$, respectively. There were significant effects of shoot thinning on canes/meter trellis decreasing from 35.55 to $33.74 / \mathrm{m}, \mathrm{p}>.048$. These findings are consistent with pruning studies that have also reported an increase in bud-burst percentage (Smart et al., 1982) and individual cane weight (Freeman et al., 1979), while canes/meter trellis 
and clusters/shoot are decreased due to severe pruning (Bowed and Kliewer, 1990). Severe pruning increases bud-burst because fewer "count-buds" are left at pruning time forcing more “non-count" buds to emerge at bud-burst (Smart et al., 1982). Severe pruning increases individual cane weight by directing its vegetative energy to fewer shoots (Bowed and Kliewer, 1990). Consistent with the findings presented in this paper is that shoot thinning will most likely reduce the number of canes/meter trellis depending on the timing (Reynolds et al., 1994a, 1994b).

Table 5. Effect of pruning and canopy treatment on vine parameters in 2009 of syrah grapevine at Trestle Vineyard, California State Polytechnic University, San Luis Obispo, CA. ${ }^{a}$

\begin{tabular}{|c|c|c|c|c|}
\hline & $\%$ Bud Burst & Clusters/Shoot & Canes/meter trellis & Average cane weight (grams) \\
\hline \multicolumn{5}{|l|}{ Pruning Treatment } \\
\hline Severe & $167 \% \mathrm{a}$ & $1.18 \mathrm{a}$ & $31.43 \mathrm{a}$ & $15.85 \mathrm{a}$ \\
\hline Standard & $75 \% \mathrm{~b}$ & $1.62 \mathrm{~b}$ & $37.52 b$ & $11.17 \mathrm{~b}$ \\
\hline Significance & $*$ & $*$ & * & $*$ \\
\hline \multicolumn{5}{|l|}{ Canopy Treatment } \\
\hline Standard & $124 \% \mathrm{a}$ & $1.35 \mathrm{a}$ & $33.74 \mathrm{a}$ & $13.78 \mathrm{a}$ \\
\hline No Shoot Thinning & $123 \% \mathrm{a}$ & $1.23 \mathrm{a}$ & $35.55 b$ & $13.58 \mathrm{a}$ \\
\hline Both Sides Leaf Removal & $115 \% \mathrm{a}$ & $1.60 \mathrm{~b}$ & $34.15 \mathrm{a}$ & $13.17 \mathrm{a}$ \\
\hline Significance & $n s$ & $*$ & $*$ & $n s$ \\
\hline
\end{tabular}
determined by Tukey's mean separation procedure.

\section{Point Quadrant Analysis}

Point quadrant analysis was conducted in 2009 approximately four weeks before harvest. Point Quadrant analysis conducted on all experimental vines showed general canopy trends of average percentage gaps, average number of leaf layers, average percent interior clusters and average percent interior leaves. Averages were reported from this experiment because only ten insertions per experimental unit (3 vine set) were measured. Average percentage gaps ranged from a low of $6 \%$ in treatment 3 (severe pruning, no shoot thinning, east side leaf removal) to a high of $24 \%$ in treatment 5 (severe pruning, no shoot thinning, both sides leaf removal) (Figure 
4). According to Smart and Robinson (1992), the optimum value for percentage gaps is between 20 and $40 \%$. Only treatments 5 and 6 (no shoot thinning, both sides leaf removal) fell within the optimum range, while treatments 3 and 4 (no shoot thinning, east side leaf removal) had the lowest average percentage gaps (Figure 4). Treatments 5 and 6 were not shoot thinned but had both sides leaf removal which increased average percentage gaps (Figure 4).

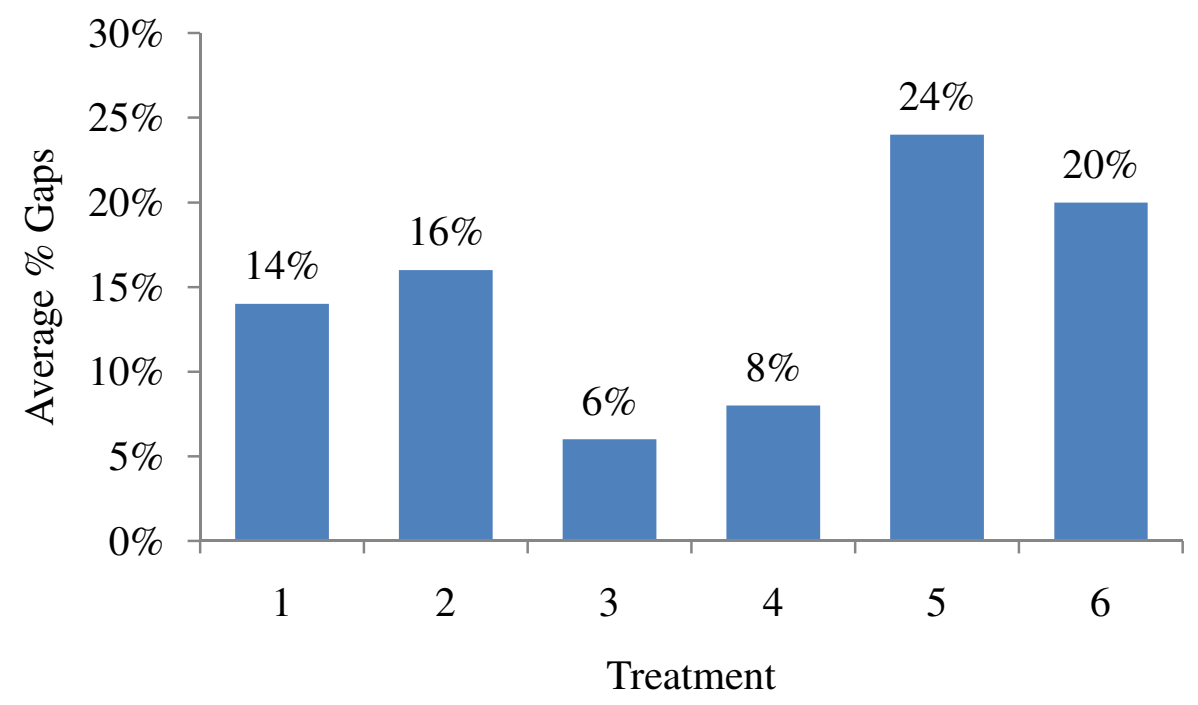

Figure 4. Effect of pruning and canopy treatment on average percentage canopy gaps in 2009 of syrah grapevine at Trestle Vineyard, California State Polytechnic University, San Luis Obispo, CA.

Average leaf layers ranged from a low of .76 in treatment 5 (severe pruning, no shoot thinning, both sides leaf removal) to a high of 2.56 in treatment 3 (severe pruning, no shoot thinning, east side leaf removal) (Figure 5). Average leaf layers were highest in treatments 3 and 4 (no shoot thinning, east side leaf removal) and lowest in treatments 5 and 6 (no shoot thinning, both sides leaf removal) (Figure 5). According to Smart and Robinson (1992), the optimum value for leaf layer numbers is between 1.0 and 1.5. None of the treatment groups had an average leaf layer number within the optimum range (Figure 5). 


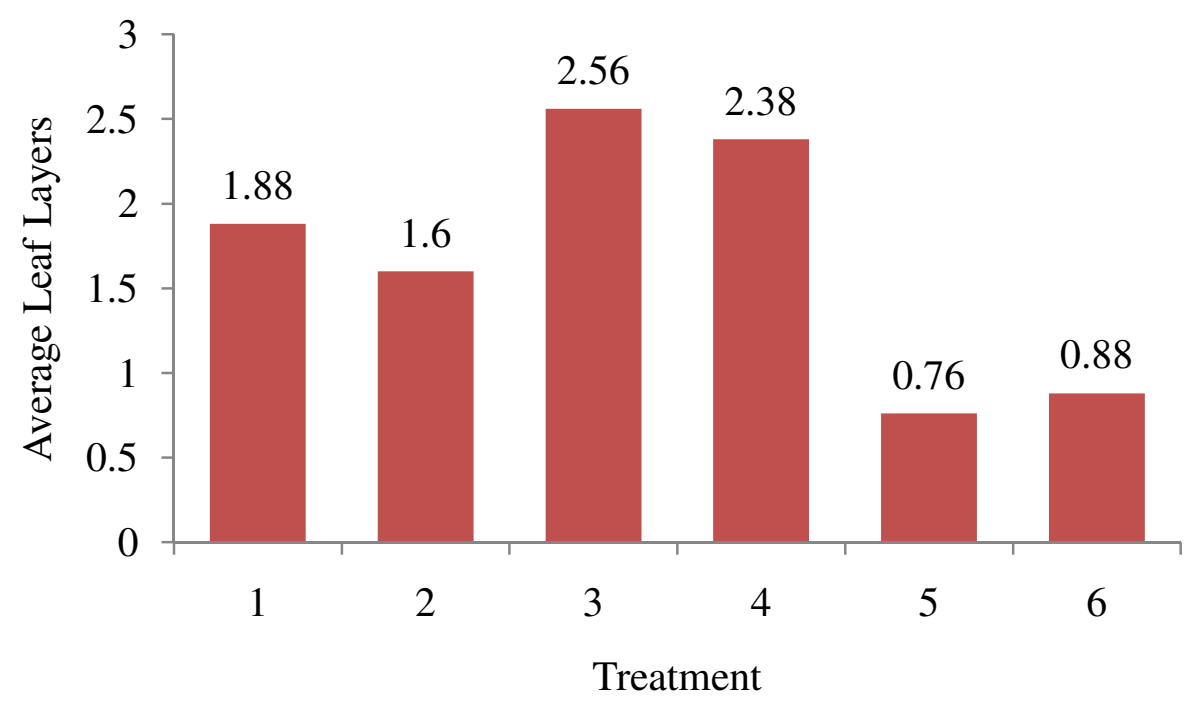

Figure 5. Effect of pruning and canopy treatment on average canopy leaf layers in 2009 of syrah grapevine at Trestle Vineyard, California State Polytechnic University, San Luis Obispo, CA.

Average percentage interior leaves ranged from a low of $9 \%$ in treatment 2 (standard pruning, shoot thinning, east side leaf removal) to a high of $25 \%$ in treatment 5 (severe pruning, no shoot thinning, both sides leaf removal) (Figure 6). Average percentage interior leaves were highest in treatments 5 and 6 (no shoot thinning, both sides leaf removal) and lowest in treatments 1 and 2 (shoot thinning,east side leaf removal). According to Smart and Robinson (1992), the optimum value for percentage interior leaves is less than 10\%; only treatment 2 (standard pruning, shoot thinning, east side leaf removal) was below that value. Average interior clusters ranged from a low of $36 \%$ in treatment 2 to a high of $62 \%$ in treatment 6 (standard pruning, no shoot thinning, both sides leaf removal). Average percentage interior clusters were highest in treatments 5 and 6 (no shoot thinning, both sides leaf removal) and lowest in treatments 1 and 2 (shoot thinning, east side leaf removal) (Figure 6). According to Smart and Robinson (1992), the optimum value for percent interior clusters is $40 \%$ or less. Only treatments 1 and 2 which were the control groups for shoot thinning in this experiment, had values within this range. 


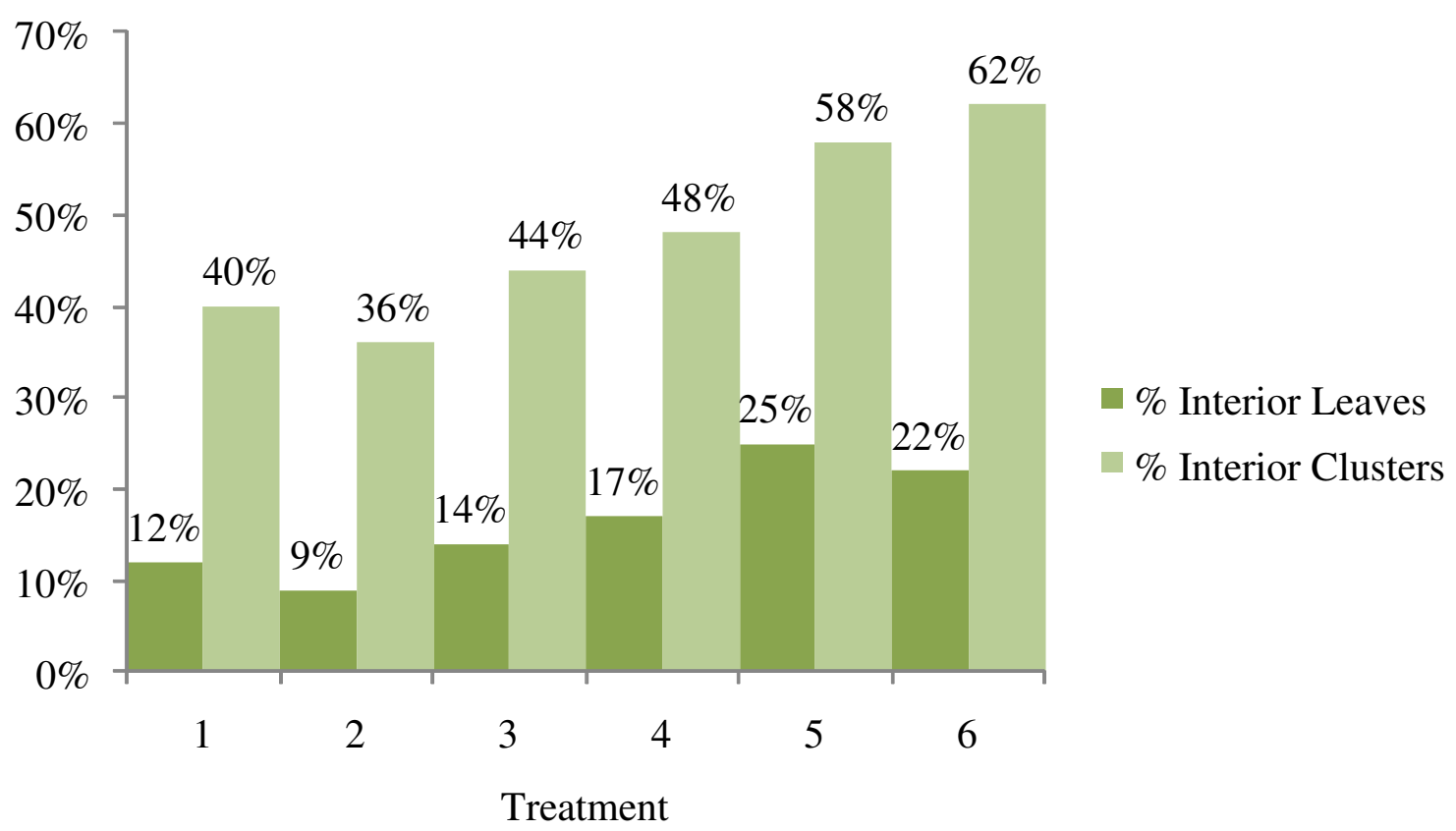

Figure 6. Effect of pruning and canopy management practices on average percentage interior leaves and interior clusters in 2009 of syrah grapevine at Trestle Vineyard, California State Polytechnic University, San Luis Obispo, CA.

\section{Repeated Measures Analysis}

To test the response of berries to seasonal and treatment differences in 2009, we measured brix, TA, Ph and weight for six weeks leading up to harvest. In 2009 there were several significant differences found based on pruning level: brix, p.H., and sugar to acid ratio as well as on the canopy treatment: TA and p.H., indicating different maturation rates (Table 6). Severe pruning increased brix accumulation from 19.91 to $22.79, \mathrm{p}>.005$, at the last sample date before harvest. Severe pruning increased $\mathrm{Ph}$ from 3.64 to $3.81, \mathrm{p}>.0125$, and sugar to acid ratio from 3.63 to $4.48, \mathrm{p}>.0054$. An increase in the accumulation rate of brix, $\mathrm{Ph}$ and sugar to acid ratio based on severe pruning indicate a quicker ripening time and was most likely due to the crop reduction forced on the vine by severe pruning as previously noted in this paper and commented on by Smart et al. (1982). 
Table 6. Effect of pruning and canopy treatment on berry maturation rates in 2009 of syrah grapevine at Trestle Vineyard, California State Polytechnic University, San Luis Obispo, CA. ${ }^{\text {a }}$

\begin{tabular}{|c|c|c|c|c|c|}
\hline & Weight (grams) & Brix (degrees) & TA $($ g. $\operatorname{tart} / 100 \mathrm{ml})$ & $\mathrm{pH}$ & Sugar to Acid Ratio \\
\hline \multicolumn{6}{|l|}{ Pruning Treatment } \\
\hline Severe & $30.22 \mathrm{a}$ & $22.79 a$ & $0.51 \mathrm{a}$ & $3.81 \mathrm{a}$ & $4.48 \mathrm{a}$ \\
\hline Standard & $28.78 \mathrm{a}$ & $19.91 b$ & $0.55 b$ & $3.64 \mathrm{~b}$ & $3.63 b$ \\
\hline Significance & $n s$ & $*$ & $*$ & $*$ & $*$ \\
\hline \multicolumn{6}{|l|}{ Canopy Treatment } \\
\hline Standard & $29.35 a$ & $20.95 a$ & $0.52 \mathrm{a}$ & $3.73 \mathrm{a}$ & $4.07 \mathrm{a}$ \\
\hline No Shoot Thinning & $30.48 \mathrm{a}$ & $21.66 \mathrm{a}$ & $0.54 \mathrm{a}$ & $3.74 \mathrm{a}$ & $4.08 \mathrm{a}$ \\
\hline Both Sides Leaf Removal & $28.68 \mathrm{a}$ & $21.45 \mathrm{a}$ & $0.54 \mathrm{a}$ & $3.72 \mathrm{a}$ & $4.02 \mathrm{a}$ \\
\hline Significance & $n s$ & $n s$ & $n s$ & $n s$ & $n s$ \\
\hline
\end{tabular}

${ }^{a}$ MANOVA indicated treatment not significantly different if $\mathrm{p}$-value was greater than 0.05 .

\section{Harvest Parameters}

A larger berry sample than what was used for the repeated measures analysis was used to measure performance indicators at harvest. The larger sample yielded similar results to the repeated measures analysis (Table 7). Severe pruning increased brix, $\mathrm{Ph}$, sugar to acid ratio and decreased TA, as was previously noted in the 2009 repeated measures analysis portion of this study but decreased TA, while shoot thinning and both sides leaf removal had no significant effects on performance indicators (Table 7) which were also consistent with repeated measures findings. With the harvest sample, severe pruning increased brix from 21.13 to $23.19, \mathrm{p}>.0142$, $\mathrm{Ph}$ from 3.62 to $3.76, \mathrm{p}>.0126$ and sugar to acid ratio from 4.10 to $4.84, \mathrm{p}>.011$. Severe pruning increased brix which is positive for vinification due to the potential increase in alcohol percentage in the finished wine. Severe pruning also increased $\mathrm{Ph}$ which is negative for vinification, potentially leading to unstable wines. Severe pruning decreased TA from .52 to .48 $\mathrm{g}$ TA/100ml, $\mathrm{p}>.0180$, which is also negative for vinification, potentially leading to unstable wines. There were no significant differences of shoot thinning on brix and sugar to acid ratio which is inconsistent with the findings by Reynolds et al. (1994a) and Reynolds et al. (2005), 
who found that shoot thinning increased soluble solids and sugar to acid ratio due in large part to the indirect effect of fruit removal. Perhaps the difference in our findings was the lower degree of shoot removal that was conducted in our experiment.

Table 7. Effect of pruning and canopy treatment on harvest berry chemistry in 2009 of syrah grapevine at Trestle Vineyard, California State Polytechnic University, San Luis Obispo, CA. ${ }^{\text {a }}$

\begin{tabular}{rcccc}
\hline & Brix (degrees) & $\mathrm{TA}(\mathrm{g} / 100 \mathrm{ml})$ & Sugar to Acid Ratio & $\mathrm{pH}$ \\
\hline Pruning Treatment & & & & \\
Severe & $23.19 \mathrm{a}$ & $0.48 \mathrm{a}$ & $4.84 \mathrm{a}$ & $3.76 \mathrm{a}$ \\
Standard & $21.13 \mathrm{~b}$ & $0.52 \mathrm{~b}$ & $4.10 \mathrm{~b}$ & $3.62 \mathrm{a}$ \\
Significance & $n s$ & $*$ & $*$ & \\
& & & & \\
Canopy Treatment & & $0.49 \mathrm{a}$ & $4.43 \mathrm{a}$ & $3.70 \mathrm{a}$ \\
Standard & $21.50 \mathrm{a}$ & $0.51 \mathrm{a}$ & $4.40 \mathrm{a}$ & $3.67 \mathrm{a}$ \\
No Shoot Thinning & $22.29 \mathrm{a}$ & $0.50 \mathrm{a}$ & $4.58 \mathrm{a}$ & $3.69 \mathrm{a}$ \\
Both Sides Leaf Removal & $22.68 \mathrm{a}$ & $n s$ & $n s$ & $n s$ \\
Significance & $n s$ & $n s$ &
\end{tabular}

${ }^{a}$ values within the same column followed by the same letter are not significantly different where $\mathrm{p}=.05$, as determined by Tukey's mean separation procedure.

Severe pruning increased total potassium (ppm), amino acid percentage (\%) of yeast assimilable nitrogen (YAN), amino acid to ammonium ratio and decreased ammonium \% of YAN (Table 8). Shoot thinning had no significant effects on potassium concentration but increased amino acid \% of YAN and the amino acid to ammonium ratio but decreased ammonium \% of YAN (Table 8). Both sides leaf removal had no significant effects on potassium concentration, amino acid \% of YAN, ammonium \% of YAN or amino acid to ammonium ratio (Table 8). Severe pruning increased potassium from 2199 to $2496 \mathrm{ppm}$, p $>.0237$, amino acid \% of YAN from $72 \%$ to $78 \%, \mathrm{p}>.0001$, amino acid to ammonium ratio from 2.60 to $3.69, \mathrm{p}>.0001$, and decreased ammonium $\%$ of YAN from 28 to $21 \% \mathrm{p}>.0001$. Shoot thinning increased amino acid percentage of YAN from 72 to $77 \%, \mathrm{p}>.001$, amino acid to ammonium ratio from 2.58 to $3.59, \mathrm{p}>.001$, and decreased ammonium percentage of YAN from 28 to $22 \%, \mathrm{p}>.001$. 
Increased levels of potassium are generally negative for vinification as it can precipitate with tartaric acid during fermentation causing increases in $\mathrm{Ph}$ which leads to instability in wine as previously noted. As a crop becomes riper, the amino acid \% of YAN and the amino to ammonium acid ratio increases while the ammonium \% of YAN decreases, as noted by GardeCerdon et al. (2009). Potassium level in berries usually increases with shade (Smart et al., 1985). Treatments 1 and 3 (severe pruning) had higher average canopy leaf layers (Figure 5) than treatments 2 and 4 (standard pruning) in 2009, indicating a more dense canopy that most likely created more shade which could be responsible for severe pruning increasing potassium concentration.

Table 8. Effect of pruning and canopy treatment on potassium and nitrogen composition of berries at harvest in 2009 of syrah grapevine at Trestle Vineyard, California State Polytechnic University, San Luis Obispo, CA. ${ }^{\mathrm{a}}$

\begin{tabular}{|c|c|c|c|c|}
\hline & Potassium (ppm) & Amino $\%$ of YAN & Ammonium $\%$ of YAN & Amino/Ammonium Ratio \\
\hline \multicolumn{5}{|l|}{ Pruning Treatment } \\
\hline Severe & $2496 a$ & $0.78 \mathrm{a}$ & $0.22 \mathrm{a}$ & $3.69 \mathrm{a}$ \\
\hline Standard & $2199 \mathrm{~b}$ & $0.72 \mathrm{~b}$ & $0.28 \mathrm{~b}$ & $2.61 \mathrm{~b}$ \\
\hline Significance & $*$ & $*$ & $*$ & * \\
\hline \multicolumn{5}{|l|}{ Canopy Treatment } \\
\hline Standard & $2496 \mathrm{a}$ & $0.77 \mathrm{a}$ & $0.23 \mathrm{a}$ & $3.59 \mathrm{a}$ \\
\hline No Shoot Thinning & $2276 a$ & $0.72 \mathrm{~b}$ & $0.28 \mathrm{~b}$ & $2.58 \mathrm{~b}$ \\
\hline Both Sides Leaf Removal & $2296 a$ & $0.76 \mathrm{a}$ & $0.24 \mathrm{a}$ & $3.28 \mathrm{a}$ \\
\hline Significance & $n s$ & $*$ & $*$ & $*$ \\
\hline
\end{tabular}

Severe pruning decreased tartaric acid (g/L) and increased malic to tartaric ratio, while shoot thinning decreased tartaric acid (g/L) and both sides leaf removal had no significant effects on malic, tartaric acid or on the malic to tartaric ratio (Table 9). Severe pruning decreased tartaric acid content in berries from 4.16 to $3.73 \mathrm{~g} / \mathrm{L}, \mathrm{p}>.0045$, and subsequently increased the malic to tartaric ratio from .51 to $.61, \mathrm{p}>.009$. Bowed and Kliewer (1990) noted that increased 
shade in the fruit zone decreases tartaric acid. Treatments 1 and 3 (severe pruning) had higher average canopy leaf layers in 2009 (Figure 5) than treatments 2 and 4 (standard pruning) indicating a more dense canopy that most likely created more shade in the fruit zone decreasing tartaric acid. Shoot thinning decreased tartaric acid from 4.22 to $3.68 \mathrm{~g} / \mathrm{L} \mathrm{p}>.0133$ which is inconsistent with Reynolds et al. (2005) who reported that shoot thinning increasing light in the canopy which would increase tartaric acid content of berries.

Table 9. Effect of pruning and canopy treatment on organic acid composition in berries at harvest in 2009 of syrah grapevine at Trestle Vineyard, California State Polytechnic University, San Luis Obispo, CA. ${ }^{\text {a }}$

\begin{tabular}{rccc}
\hline & Malic Acid $(\mathrm{g} / \mathrm{L})$ & Tartaric Acid $(\mathrm{g} / \mathrm{L})$ & Malic/Tartaric Ratio \\
\hline Pruning Treatment & & & \\
Severe & $2.21 \mathrm{a}$ & $3.73 \mathrm{a}$ & $0.61 \mathrm{a}$ \\
Standard & $2.09 \mathrm{a}$ & $4.16 \mathrm{~b}$ & $0.51 \mathrm{~b}$ \\
Significance & $n s$ & $*$ & $*$ \\
Canopy Treatment & & & \\
Standard & $2.11 \mathrm{a}$ & $3.68 \mathrm{a}$ & $0.59 \mathrm{a}$ \\
No Shoot Thinning & $2.11 \mathrm{a}$ & $4.22 \mathrm{~b}$ & $0.51 \mathrm{a}$ \\
Both Sides Leaf Removal & $2.25 \mathrm{a}$ & $3.95 \mathrm{a}$ & $0.58 \mathrm{a}$ \\
Significance & $n s$ & $n s$ & $n s$ \\
\hline a
\end{tabular}

${ }^{a}$ values within the same column followed by the same letter are not significantly different where $p=.05$, as determined by Tukey's mean separation procedure.

Severe pruning increased tannin, anthocyanins and tannin to anthocyanins ratio of berries at harvest 2009 (Table 10). Shoot thinning and both sides leaf removal had no significant effects on tannin, anthocyanins or tannin to anthocyanins ratio (Table 10). Severe pruning increased tannin from 388 to $752 \mathrm{ppm}, \mathrm{p}>.0024$, anthocyanins from 143 to $183 \mathrm{ppm}, \mathrm{p}>.0077$ and the tannin to anthocyanins ratio from 1.38 to 1.92 , p>.0297. Generally, both severe pruning and shoot thinning will decrease anthocyanins (Freeman, 1983) (Reynolds et al., 1996). Our results are inconsistent with these studies perhaps because our experiment was conducted in San Luis Obispo, CA, which is considered a cool climate for grape growing. Generally, more anthocyanins will develop in a cool climate compared to a warm climate. The di-oxygenated 
group of tannin that includes catechin generally increases with shade and the tri-oxygenated group of anthocyanins that includes malividin has the tendency to decrease with shade (Ristic et al., 2007) (Downey et al., 2004). This is consistent with our results and further supports that treatments 1 and 3 (severe pruning) had increased levels of shade (Figure 4) (Figure 5) compared to treatments 2 and 4. This would also support why tannin, reported in catechin equivalents, almost doubled in response to severe pruning and why anthocyanins increased to a much lower degree (Table 10).

Table 10. Effect of pruning and canopy treatment on proanthocyanidin composition in berries at harvest in 2009 of syrah grapevine at Trestle Vineyard, California State Polytechnic University, San Luis Obispo, CA. ${ }^{\text {a }}$

\begin{tabular}{rccc}
\hline & Tannin $(\mathrm{ppm})$ & Anthocyanins $(\mathrm{ppm})$ & Tannin/Anthocyanins Ratio \\
\hline Pruning Treatment & & & \\
Severe & $752 \mathrm{a}$ & $183 \mathrm{a}$ & $1.92 \mathrm{a}$ \\
Standard & $388 \mathrm{~b}$ & $143 \mathrm{~b}$ & $1.38 \mathrm{~b}$ \\
Significance & $*$ & $*$ & $*$ \\
& & & \\
Canopy Treatment & $556 \mathrm{a}$ & $166 \mathrm{a}$ & $1.61 \mathrm{a}$ \\
Standard & $462 \mathrm{a}$ & $144 \mathrm{a}$ & $1.53 \mathrm{a}$ \\
No Shoot Thinning & $692 \mathrm{a}$ & $179 \mathrm{a}$ & $1.82 \mathrm{a}$ \\
Both Sides Leaf Removal & $n s$ & $n s$ & $n s$ \\
Significance & $n s$ &
\end{tabular}

${ }^{a}$ values within the same column followed by the same letter are not significantly different where $\mathrm{p}=.05$, as determined by Tukey's mean separation procedure.

Severe pruning significantly increased total phenolics, color density and had no significant effect on color hue (Table 11). Both shoot thinning and both sides leaf removal had no significant effects on total phenolics, color hue or color density (Table 11). Severe pruning increased total phenolics and color density, based on relative absorbance from 26.49 to 33.44 , $\mathrm{p}>.010$ and from 6.95 to $9.63, \mathrm{p}>.010$. Severe pruning increased total phenolics because of the increased shade already noted in treatments 1 and 3 compared to 2 and 4 (Figures 4, 5). Because tannins are the largest class of phenolics in the berry and catechin is part of the di-oxygenated group that decreases with shade, it can be hypothesized that due to the increased shade caused by 
severe pruning total phenolics were increased. Severe pruning increased color density most likely due to the indirect effect of crop reduction associated with severe pruning that has been noted several times in this paper.

Table 11. Effect of pruning and canopy treatment on total phenolic content, color hue and density of berries at harvest in 2009 of syrah grapevine at Trestle Vineyard, California State Polytechnic University, San Luis Obispo, CA. ${ }^{\mathrm{a}, \mathrm{b}}$

\begin{tabular}{rccc}
\hline & Total Phenolics & Color Hue & Color Density \\
\hline Pruning Treatment & & & \\
Severe & $33.44 \mathrm{a}$ & $0.50 \mathrm{a}$ & $9.63 \mathrm{a}$ \\
Standard & $26.49 \mathrm{~b}$ & $0.53 \mathrm{a}$ & $6.95 \mathrm{~b}$ \\
Significance & $*$ & $n s$ & $*$ \\
& & & \\
Canopy Treatment & & & $8.75 \mathrm{a}$ \\
Standard & $30.19 \mathrm{a}$ & $0.50 \mathrm{a}$ & $7.13 \mathrm{a}$ \\
No Shoot Thinning & $28.36 \mathrm{a}$ & $0.55 \mathrm{a}$ & $9.03 \mathrm{a}$ \\
Both Sides Leaf Removal & $31.34 \mathrm{a}$ & $0.49 \mathrm{a}$ & $n s$ \\
Significance & $n s$ & $n s$ & $\mathrm{n}$ \\
\hline
\end{tabular}

${ }^{a}$ values within the same column followed by the same letter are not significantly different where $\mathrm{p}=.05$, as

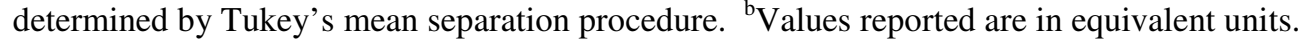

Severe pruning decreased total yield, yield/meter trellis and Ravaz index in 2009 (Table 12). Severe pruning decreased both total yield (kg) from 16.16 to $9.19, \mathrm{p}>.0001$ and yield/meter trellis $(\mathrm{kg} / \mathrm{m})$ from 4.50 to $2.47 \mathrm{~kg} / \mathrm{m}, \mathrm{p}>.0005$. Severe pruning did not affect pruning weights but did significantly decrease Ravaz index from 12.36 to 5.14, $\mathrm{p}>.0001$ which is in the target range for premium grapes (Table 12). Both shoot thinning and both sides leaf removal did not significantly affect total yield, yield/meter trellis, pruning weights or Ravaz index.

The findings in this paper agree with the majority of studies involving severe pruning where a yield decrease was observed (Smart et al., 1982) (Byrne and Howell, 1978). The decrease in yield observed with severe pruning is due to the fewer clusters that are set by grapevines in response to fewer buds left during winter pruning (Bowed and Kliewer, 1990). Based on point quadrant averages (Figures $4,5,6$ ) it can be concluded that there were different 
levels of shade in the canopy based on pruning level which did not have significant effects on pruning weights. This finding agrees with Smart et al. (1985), who found that differing degrees of shade had no significant effect on pruning weights. Additionally, previous studies by Freeman et al. (1979) and Myers et al. (2008) found that pruning weights are not always affected by different pruning levels or different shoot densities due to the grapevines ability to redirect energy into fewer shoots. The findings in this paper are not consistent with Naor et al. (2002) and Reynolds et al. (1994a) who found that shoot thinning tends to decrease Ravaz index values. The inconsistency in findings could be due to the lower degree of shoot removal conducted in this experiment.

Figure 12. Effect of pruning and canopy treatment on yield parameters in 2009 of syrah grapevine at Trestle Vineyard, California State Polytechnic University, San Luis Obispo, CA.

\begin{tabular}{rccc}
\hline & Yield/Repetition $(\mathrm{kg})$ & Yield/Meter Trellis $(\mathrm{kg} / \mathrm{m})$ & Ravaz Index** \\
\hline Pruning Treatment & & & \\
Severe & $9.19 \mathrm{a}$ & $2.47 \mathrm{a}$ & $5.14 \mathrm{a}$ \\
Standard & $16.16 \mathrm{~b}$ & $4.50 \mathrm{~b}$ & $12.36 \mathrm{~b}$ \\
Significance & $*$ & $*$ & $*$ \\
& & & \\
Canopy Treatment & & & $9.70 \mathrm{a}$ \\
Standard & $13.22 \mathrm{a}$ & $3.72 \mathrm{a}$ & $8.63 \mathrm{a}$ \\
No Shoot Thinning & $12.87 \mathrm{a}$ & $3.71 \mathrm{a}$ & $7.92 \mathrm{a}$ \\
Both Sides Leaf Removal & $11.94 \mathrm{a}$ & $3.03 \mathrm{a}$ & $n s$ \\
Significance & $n s$ & $n s$ &
\end{tabular}

a values within the same column followed by the same letter are not significantly different where $p=.05$, as determined by Tukey's mean separation procedure. **Ravaz index should be looked at on a relative and not an absolute basis due to the vine "tipping" conducted as a management practice. 


\section{Summary of Ripeness Ratios 2009}

Severe pruning increased the following ratios: sugar to acid, amino acid to ammonium, tannin to anthocyanin and malic to tartaric (Table 13). Shoot thinning had no significant effects on any of the ripeness ratios except for increasing the amino acid to ammonium ratio. Both sides leaf removal had no significant effects on any of the ripeness ratios. Based on these ripening ratios it appears that severe pruning increased the ripening speed due primarily to the crop reduction observed. All of the ripening ratios that were increased by severe pruning are beneficial to vinification except for the malic to tartaric ratio which could lead to instability of wine.

Table 13. Effect of pruning and canopy treatment on ripeness ratios in 2009 of syrah grapevine at Trestle Vineyard, California State Polytechnic University, San Luis Obispo, CA. ${ }^{\text {a }}$

\begin{tabular}{rcccc}
\hline & Sugar/Acid & Amino Acid/Ammonium & Tannin/Anthocyanins & Malic/Tartaric \\
\hline Pruning Treatment & & & & \\
Severe & $4.80 \mathrm{a}$ & $3.69 \mathrm{a}$ & $1.92 \mathrm{a}$ & $0.61 \mathrm{a}$ \\
Standard & $4.10 \mathrm{~b}$ & $2.61 \mathrm{~b}$ & $1.38 \mathrm{~b}$ & $0.51 \mathrm{~b}$ \\
Significance & $*$ & $*$ & $*$ & $*$ \\
Canopy Treatment & & & & \\
Standard & $4.30 \mathrm{a}$ & $3.59 \mathrm{a}$ & $1.61 \mathrm{a}$ & $0.59 \mathrm{a}$ \\
No Shoot Thinning & $4.40 \mathrm{a}$ & $2.58 \mathrm{a}$ & $1.53 \mathrm{a}$ & $0.51 \mathrm{a}$ \\
Both Sides Leaf Removal & $4.60 \mathrm{a}$ & $3.28 \mathrm{a}$ & $1.82 \mathrm{a}$ & $0.58 \mathrm{a}$ \\
Significance & $n s$ & $n s$ & $n s$ & $n s$ \\
\hline
\end{tabular}

${ }^{a}$ values within the same column followed by the same letter are not significantly different where $\mathrm{p}=.05$, as determined by Tukey's mean separation procedure.

\section{Conclusion}


In 2008, repeated measures analysis showed no significant effects of severe pruning, shoot thinning or both sides leaf removal on maturation rate of performance indicators. At harvest 2008, severe pruning caused a decrease in yield/meter trellis and Ravaz index. Differences between treatments in the first year of the experiment were not expected as Vitis vinifera is able to compensate to pruning management changes in the short term. Additionally, no differences were found in maturation speeds, indicating that shoot thinning did not make a significant difference in the way that the grapes developed on the basis of weight, $\mathrm{Ph}$, sugar, and TA in year 1 of our study.

In 2009, repeated measures analysis showed significant effects of severe pruning increasing brix, $\mathrm{Ph}$ and sugar to acid ratio while shoot thinning and both sides leaf removal had no significant effects on performance indicators. At harvest 2009, severe pruning increased brix, $\mathrm{Ph}$, tannin, anthocyanins, phenolics, color density, potassium, amino acid \% of YAN, and the following ratios: sugar/acid, amino acid/ammonium, tannin/anthocyanin and malic/tartaric acid. Severe pruning also decreased tartaric acid, yield/meter trellis, ammonium $\%$ of YAN and Ravaz index.

There were two performance indicators that yielded consistent results in both years of this experiment; yield/meter trellis and Ravaz index. Although Vitis vinifera has the ability to compensate in the short-term to pruning or canopy management practices, severe pruning was not compensated for in year 1 as it decreased yield/meter trellis and Ravaz index. Severe pruning also decreased yield/meter trellis and Ravaz index in year 2 of this study. This was most likely due to the reduced yield forced on the vine by severe pruning and was only expected in year 1 of this study. 
Data from year 2 of research indicated that severe pruning will speed up many physiological processes and produce a ripe crop earlier than with standard pruning practices. This is due primarily to the yield reduction that occurs with severe pruning. Severe pruning generally reduces yield and clusters/shoot and increases individual berry and cluster size. The findings presented in this thesis suggest that severe pruning could be used as a tool in viticulture areas with short growing seasons. Ripening parameters are not always able to reach the levels desired by viticulturists in areas with short growing seasons. If severe pruning was used in these areas a higher quality crop might be realized before inclement weather arrived. Also, because severe pruning decreases yield/vine, cost savings would be realized in areas where a crop thinning pass is normally conducted. Additionally, because no significant differences were observed in the way fruit chemistry matured in year 1 of our study, we can consider using one of the labor savings canopy management tactics as a labor saving tool but not for consecutive years. Additional research that looks at severe pruning as a tactic in areas with short growing seasons should include irrigation and management practices that reduce berry size beneficial for vinification as severe pruning generally increases berry size. 


\section{LITERATURE CITED}

Adams, D.O. 2006. Phenolics and ripening in grape berries. Am. J. Enol. Vitic. 57 (3) : 249-256.

Archer, E. and D.V. Schalkwyk. 2007. The effect of alternative pruning methods on the viticultural and oenological performance of some wine grape varieties. S. Afr. J. Enol. Vitic. 28 (2) : 107-139.

Baker, B., 2010. Baker Wine and Grape Analysis. Paso Robles. CA. personal communication.

Bavaresco, L., M. Gatti, S. Pezzutto, M. Fregoni, and F. Mattivi. 2008. Effect of leaf removal on grape yield, berry composition, and stilbene. 2008. Am. J. Enol. Vitic. (59) 3 : 292-298.

Bishop, C.S. and A. Dye. 1982. Microwave heating enhances the migration of plasticizers out of plastics. Journal of Environment and Health. (44) 5 : 231.235.

Boss, P.K., C. Davies, and S.P. Robinson. 1996. Analysis of the expression of anthocyanin pathway genes in developing Vitis vinifera L. c.v. Shiraz grape berries and the implication for pathway regulation. Plant Physiol. 111 : 1059-1066.

Bowed, P.A. and W.M. Kliewer. 1990. Influence of clonal variation, pruning severity, and cane structure on yield component development in 'Cabernet Sauvignon' grapevines. J. Amer. Soc. Hort. Sci. 115 (4) : 530-534.

Brancadora, L., L. Valenti, A. Reina, and A. Scienza. 1994. Potassium content of grapevine during the vegetative period: the role of the rootstock. J. Plant Nutrition. 17 (12) : 2165 2175.

Brown, W., 2008. California State Polytechnic University. San Luis Obispo. CA. personal communication.

Bureau, S.M., R.L. Baumes, and A.J. Razungles. 2000. Effects of vine or bunch shading on the glycosylated flavor precursors in grapes of Vitis vinifera L. c.v. Syrah. J. Agric. Food Chem. 48 : 1290-1297.

Byrne, M.E. and G.S. Howell. 1978. Initial response of Baco Noir grapevines to pruing severity, sucker removal and weed control. Am. J. Enol. Vitic. 29 (3) : 192-198.

Cheynier, V., M. Duenas-Paton, E. Salas, C. Maury, J.-M. Souguet, P. Sarni-Manchado, and H. Fulcrand. 2006. Structure and properties of wine pigments and tannins. Am. J. Enol. Vitic. 57 (3) : 298-305.

Cortell, J.M. and J.A. Kennedy. 2006. Effect of shading on accumulation of flavonoid compounds in (Vitis vinifera L.) Pinot Noir fruit and extraction in a model system. J. Agric. Food Chem. 54 : 8510-8520. 
Cortell, J. M., H. K. Sivertsen, J.A. Kennedy, and H. Heymann. 2008. Influence of vine vigor on Pinot noir fruit composition, wine chemical analysis, and wine sensory attributes. Am. J. Enol. Vitic. 59 (1) : 1-10.

Cortell, J.M., M. Halblieb, A.V. Gallagher, T.L. Righetti, and J.A Kennedy. 2007. Influence of vine vigor on grape (Vitis vinifera L. Cv. Pinot Noir) anthocyanins. 1. Anthocyanin concentration and composition in fruit. J. Agric. Food Chem. 55 (16) : 6575-6584.

Davies, C., R. Shin, W. Lui, M.R. Thomas, and D.P. Schachtman. 2006. Transporters expressed during grape berry (Vitis vinifera L.) development are associated with an increase in berry size and berry potassium accumulation. J. Exper. Bot. 57 (12) : 3209-3216.

Dixon-Anderson, L., R.J. Hernandez, I Gray, and B. Harte. 1988. Release of components from a plastic container during microwave heating. Packing Technology and Science. (1) 117121.

Dokoozlian, N.K. and W.M. Kliewer. 1996. Influence of light on grape berry growth and composition varies during fruit development. J. Amer. Soc. Hort. Sci. 121 (5) : 869-874.

Downey, M.O., N.K. Dokoozlian, and M.P Krstic. 2006. Cultural practice and environmental impacts on the flavonoid composition of grapes and wine: a review of recent research. Am. J. Enol. Vitic. 57 (3) : 257-268.

Downey, M.O., J.S. Harvey, and S.P. Robinson. 2004. The effect of bunch shading on berry development and flavonoid accumulation in Shiraz grapes. Aus. J. Grape Wine Res. 10 : $55-73$.

Freeman, B.M. 1983. Effects of irrigation and pruning of Shiraz grapevines on subsequent red wine pigments. Am. J. Enol. Vitic. 34 (1) : 23-26.

Freeman, B.M. T.H. Lee, and R. Turkington. 1979. Interaction of irrigation and pruning level on growth and yield of Shiraz vines. Am. J. Enol. Vitic. 30 (3) : 218-223.

Friend, A. P. and M.C.T. Trought. 2007. Delayed winter spur pruning in New Zealand can alter yield components of Merlot grapevines. Aust. J. Grape Wine Res. 13: 157-164.

Garde-Cerdon, T., C. Lorenzo, J.F. Lara, F. Pardo, C. Ancin-Azpilicueta, and M.R. Salinas. 2009. Study of the evolution of nitrogen compounds during grape ripening. Application to differentiate grape varieties and cultivated systems. J. Agric. Food Chem. 57 : 24102419.

Hanlin, R.L., and M.O. Downey. 2009. Condensed tannin accumulation and composition in skin of Shiraz and Cabernet Sauvignon grapes during berry development. Am. J. Enol. Vitic. $60(1): 13-23$. 
Harbertson, J.F., E.A. Picciotto, and D.O. Adams. 2003. Measurement of polymeric pigments in grape berry extracts and wines using a protein precipitation assay combined with bisulfate bleaching. Am. J. Enol. Vitic. 54 (4) : 301-306.

Iacono, F., A.D. Porro, A. Scienza, and G., Stringari. 1995. Differential effects of canopy manipulation and shading of Vitis vinifera L. c.v. Cabernet Sauvignon: plant nutritional status. J. Plant Nutrition. 18 (9) : 1785-1796.

Iland, P.G. and B.G. Coombe. 1988. Malate, tartrate, potassium, and sodium in flesh and skin of Shiraz grapes during ripening: Concentration and compartmentation. Am. J. Enol. Vitic. 39 (1) : 71-76.

Jensen, J.S., S. Demiray, M. Egebo, and A.S. Meyer. 2008. Prediction of wine color attributes from the phenolic profiles of red grapes (Vitis vinifera). J. Agri. Food Chem. 56 : 11051115 .

Keller, M. and G. Hrazdina. 1998. Interaction of nitrogen availability during bloom and light intensity during veraison. II Effects on anthocyanin and phenolic development during grape ripening. Am. J. Enol. Vatic. 49 (3) : 341-349.

Koyama, K. and N. Goto-Yamamoto. 2008. Bunch shading during different developmental stages affects the phenolic biosynthesis in berry skins of 'Cabernet Sauvignon' grapes. J. Amer. Soc. Hort. Sci. 133 (6) : 743-753.

Marschner, H. 1995. Second edition. Mineral nutrition of higher plants. Elsevier Ltd. Hungary. p. 101 and p.309

Mayr, E. 1985. The growth of biological thought: diversity, evolution and inheritance. Harvard University Press. Cambridge. Massachusetts.

Mori, K., S. Sugaya, and H. Gemma. 2005. Decreased anthocyanin biosynthesis in grape berries grown under elevated night temperature condition. Scientia Horticulturae. 105 : 319-330.

Myers, J.K., J.A. Wolpert, and G.S. Howell, 2008. Effect of shoot number on the leaf area and crop weight relationship of young Sangiovese grapevines. Am. J. Enol. Vitic. 59 (4) : 422-424.

Naor, A., Y. Gal, and B. Bravdo. 2002. Shoot and cluster thinning influence vegetative growth, fruit yield, and wine quality of "Sauvignon blanc" grapevines. J. Amer. Soc. Hort. Sci. 127 (4) : 628-634.

Nunan, K.J., I.M. Sims, A. Baric, S.P. Robinson, and G.B. Fischer. 1998. Changes in cell wall composition during ripening grape berries. Plant Physiology. 118: 783-792. 
Ortega-Regules, A., J.M. Ros-Garcia, A.B. Bautista-Ortin, J.M. Lopez-Roca and E. GomezPlaza. 2008. Changes in skin cell wall composition during the maturation of four premium wine grape varieties. J. Sci. Food Agric. 88 : 420-428.

Pereira, G.E., J.-P. Gaudillere, P. Pieri, G. Hilbert, M. Maucourt, C. Deborde, A. Moing, and D. Rolin. 2006. Microclimate influence on mineral and metabolic profiles of grape berries. J. Agri. Food Chem. 54: 6765-6775.

Poni, S., L. Casalini, F. Bernizzoni, S. Civardi, and C. Intrieri. 2006. Effects of early defoliation on shoot photosynthesis, yield components and grape composition. Am. J. Enol. Vitic. $57: 397-407$.

Pratelli, R., B. LaCombe, L. Torregrosa, F. Gaymard, C. Romieu, J.-B. Thibaud, and H. Sentenac. 2002. A grapevine gene encoding a guard cell $\mathrm{K}^{+}$channel displays developmental regulation in the grapevine berry. Plant Physiology. 128 : 564-577.

Reynolds, A.G., D.A. Wardle, and M. Dever. 1994a. Shoot density effects on Riesling grapevines: interactions with cordon age. Am. J. Enol. Vitic. 45 (4) : 435-443.

Reynolds, A.G., D.A. Wardle, and M. Dever. 1994b. Shoot density affects "Reisling" grapevines. I. Vine performance. J. Amer. Soc. Hort. Sci. 119 (5) : 874-880.

Reynolds, A.G., T. Molek, and C. De Savigny. 2005. Timing of shoot thinning in Vitis vinifera: impacts on yield and fruit composition variables. Am. J. Enol. Vitic. 56 (4) : 343-356.

Reynolds, A.G., S. Yerle, B. Watson, S.F. Price, and D. A. Wardle. 1996. Fruit environment and crop level effects on Pinot noir. III. Composition and descriptive analysis of Oregon and British Columbia wines. Am J. Enol. Vitic. 47 (3) : 329-339.

Ristic, R., M.O. Downey, P.G. Iland, K. Bindon, I.L. Francis, M. Herderich, and S. P. Robinson. 2007. Exclusion of sunlight from Shiraz grapes alters wine colour, tannin and sensory properties. Aust. J. Grape Wine Res. 13 : 53-65.

Roggero, J.P., S. Coen, and B. Ragonnet. 1986. High performance liquid chromatography survey on changes in pigment content in ripening grapes of Syrah. An approach to anthocyanin metabolism. Am. J. Enol. Vitic. 37 (1) : 77-83.

Rogiers, S.Y., J.M. Hatfield, V.G. Jaudzems, R.G. White, and M. Keller. 2004. Grape berry c.v. Shiraz epicuticular wax and transpiration during ripening and pre harvest weight loss. Am. J. Enol. Vitic. 55 (2) : 121-127.

Rogiers, S.Y., M. Keller, B. P. Holzapfel, and J. M. Virgona. 2000. Accumulation of potassium and calcium by ripening berries on field vines of Vitis vinifera L. Cv. Shiraz. Aust. J. Grape Wine Res. 6 : 240-243. 
Smart, R.E. 1985. Principles of grapevine canopy microclimate manipulation with implications for yield and quality. Am. J. Enol. Vitic. 36 (3) : 230-239.

Smart, R.E., J.B. Robinson, G.R. Due, and C.J. Brien. 1985. Canopy microclimate modification for the cultivar Shiraz. I. Definition of canopy microclimate. Vitis. 24 : 17-31.

Smart, R.E. and M. Robinson. 1992. Sunlight into wine. A handbook for winegrape canopy management. Winetitles, Adelaide.

Steinmaus, S. 2007. Ecological Biometrics Handbook. p. 60

Thomas, T.R., K.A. Shackel, and M.A. Matthews. 2008. Mesocarp cell turgor in Vitis vinifera L. berries throughout development and its relation to firmness, growth, and the onset of ripening. Planta. 228 : 1067-1076.

USDA, 2010. Grape Crush Report. 2008.

Weber, E.A., Trouillas, F.P., and Gubler, W.D. 2007. Double pruning of grapevines: A cultural practice to reduce infections by Eutypa lata. Am. J. Enol. Vitic. 58 (1) : 61-66.

Yilmaz, Y. and R.T. Toledo. 2004. Major flavonoids in grape seeds and skins: antioxidant capacity of catechin, epicatechin, and gallic acid. J. Agri. Food Chem. 52 : 255-260.

Yokotsuka, K. and M. Fukui. 2002. Changes in nitrogen compounds in berries of six grape cultivars during ripening over two years. Am. J. Enol. Vitic. 53 (1) : 69-77

Zoecklein, B.W., K.C. Fugelsang, B.H. Gump, and F.S. Nury. 1995. Wine analysis and production. Chapman and Hall, New York. NY. 


\section{DEFINITION OF TERMS}

Count Buds- Those buds that are counted/planned for during winter pruning.

Must- Pre-fermentation grape juice, skins and seeds.

Non-Count Buds- Those buds that are not counted/planned for during winter pruning.

Point Quadrant Analysis- Canopy assessment tool used to determine vine characteristics.

Ravaz Index- Fruit to pruning weight ratio used to determine vine balance.

Tartaric Acid-An organic acid naturally occurring in grapes.

Titratable Acidity-An estimation of a solutions total acidity.

Verasion- Start of phase III of berry growth coinciding with color change of berries.

Vinification- The process whereby fermentation changes grape juice into wine.

Yeast Assimable Nitrogen (YAN)- Ammonia and amino acid forms of nitrogen consumed by yeast during fermentation. 


\section{APPENDIX 1}

\section{Tannin Procedure}

$\underline{\text { Tannin Measurement- James F. Harbertson and Douglas O. Adams Tannin Assay Procedure }}$

All Chemicals were analytical grade and purchased from VMR (Westchester, PA).

- Bovine Serum Albumin (BSA, lyophilized powder)

- Sodium Dodecyl Sulfate (SDS, laurel sulfate, 95\%)

- Triethanolamine (TEA, 98\%)

- $\quad$ Feric Chloride Hexahydrate (FCH, 98\%)

- (+) Catechin Hydrate (CH, 98\%, powder)

All reactions performed at room temperature.

Standard Curve

1. Take from 0 to 600 micro liters of standard catechin solution in 100 micro liter increments and adjust the volume to 1750 micro liters with Re-suspension Buffer.

2. Add 250 micro liters of the Ferric Chloride Reagent and mix.

3. Allow to react for 10 minutes.

4. Read absorbance at $510 \mathrm{~nm}$.

5. Subtract the Blank (the 0 micro liter Catechin sample) absorbance from every reading.

6. Plot Catechin concentration vs. Absorbance at $510 \mathrm{~nm}$.

\section{Boiled Must Sample Extract}

1. Prepare Protein Solution by dissolving BSA into Washing Buffer.

2. Dilute sample in Model Wine Buffer.

3. For each wine sample, pipette $1 \mathrm{~mL}$ of the protein Solution into a microfuge tube and then add 500 micro liters of diluted sample. React for 15 to 30 minutes with slow agitation.

4. Centrifuge samples for 5 minutes in the microfuge (14,000 RPM).

5. Carefully pour off the supernatant, retaining the pellet in the microfuge tube.

6. Slowly add 250 micro liters of the Washing Buffer to the pelleted sample.

7. Centrifuge for 1 minute (14,000 RPM).

8. Carefully pour off the supernatant and then add 875 micro liters of Re-suspension Buffer and react for 10 minutes.

9. Mix the tube until the pellet is completely dissolved.

10. After dissolving the pellet, let the solution stand for 10 minutes and then read the absorbance at $510 \mathrm{~nm}$ (Background $\mathrm{A}_{510}$ ) before adding the Ferric Chloride Solution. Record the value. Then add 125 micro liters of the Ferric Chloride Solution, mix the sample, leave for 10 minutes and the re-read the absorbance at $510 \mathrm{~nm}$, (Final $\left.\mathrm{A}_{510}\right)$.

11. The amount of tannin in samples is calculated using the standard curve, after subtracting the background absorbance (the one obtained before the Ferric Chloride Reagent addition) and subtracting the Blank from the final absorbance (after adding the Ferric Chloride Reagent). 


\section{APPENDIX 2}

\section{Catechin/Tannin Standard Curve}

\begin{tabular}{cc}
\hline Concentration & Absorbance \\
\hline 0 & 0 \\
100 & 0.244 \\
200 & 0.554 \\
300 & 0.773 \\
400 & 1.009 \\
500 & 1.316 \\
600 & 1.536 \\
\hline
\end{tabular}

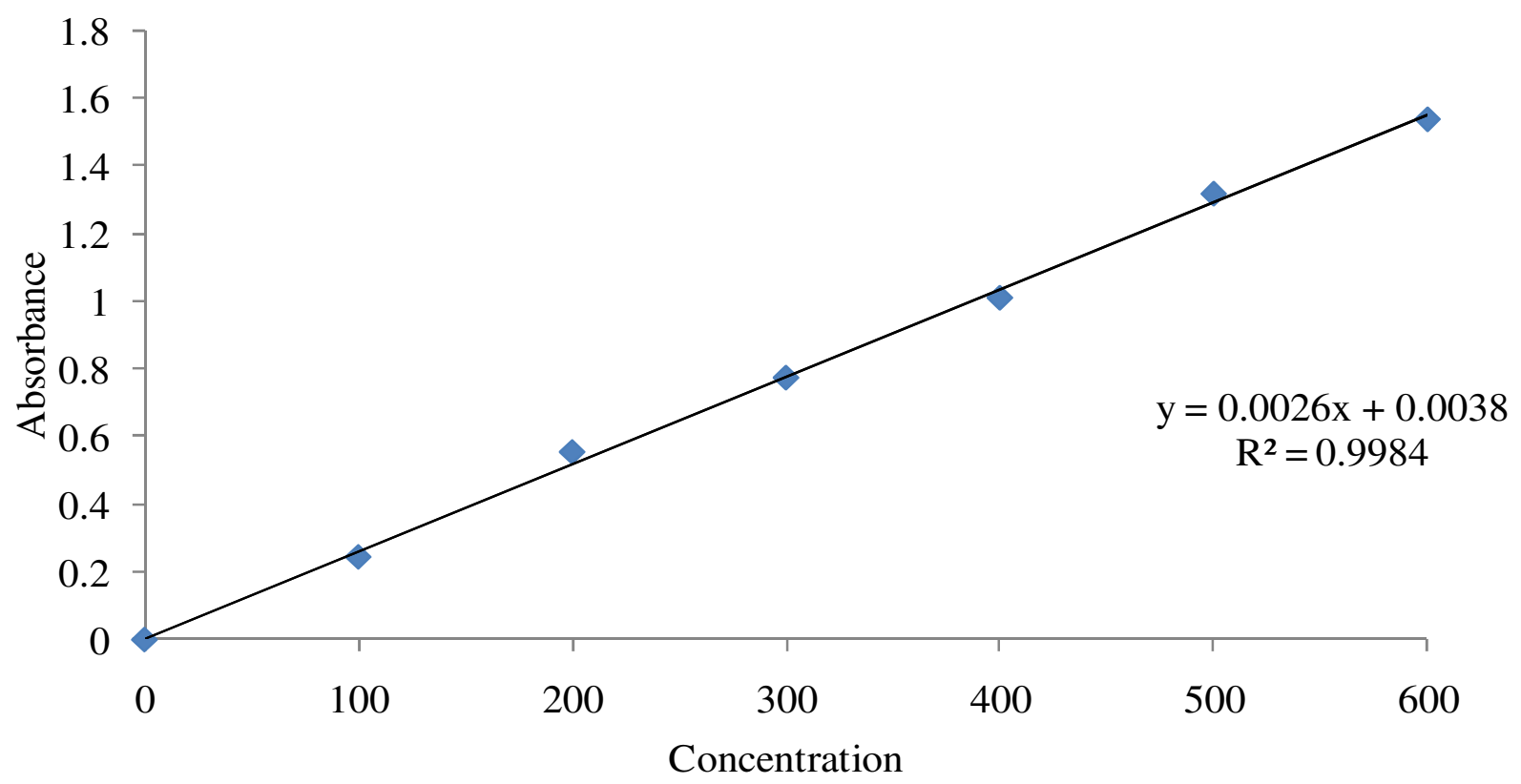

Figure 7. Diagram of a standard curve for catechin. 


\section{APPENDIX 3}

\section{Anthocyanin Procedure}

All Chemicals were analytical grade and purchased from VMR (Westchester, PA).

- pH 1.0 Buffer, Potassium Chloride-Hydrochloric Acid (KCL-HCL)

All reactions performed at room temperature.

1. Create a Standard Curve using Malvidin-3-glucoside standard.

2. Dilute $1 \mathrm{ml}$ juice samples with $\mathrm{pH} 1.0$ buffer in a $100 \mathrm{ml}$ flask.

3. Mix thouroughly and measure the absorbance at $520 \mathrm{~nm}$ with a $1 \mathrm{~cm}$ cell.

4. Plot Malvidin concentration vs. Absorbance at $520 \mathrm{~nm}$. 


\section{APPENDIX 4}

Malvidin-3-Glucoside Standard Curve

\begin{tabular}{cc}
\hline Concentration & Absorbance \\
\hline 0 & 0 \\
10 & 0.55 \\
25 & 1.65 \\
50 & 2.68 \\
75 & 3.6 \\
100 & 5.02 \\
\hline
\end{tabular}

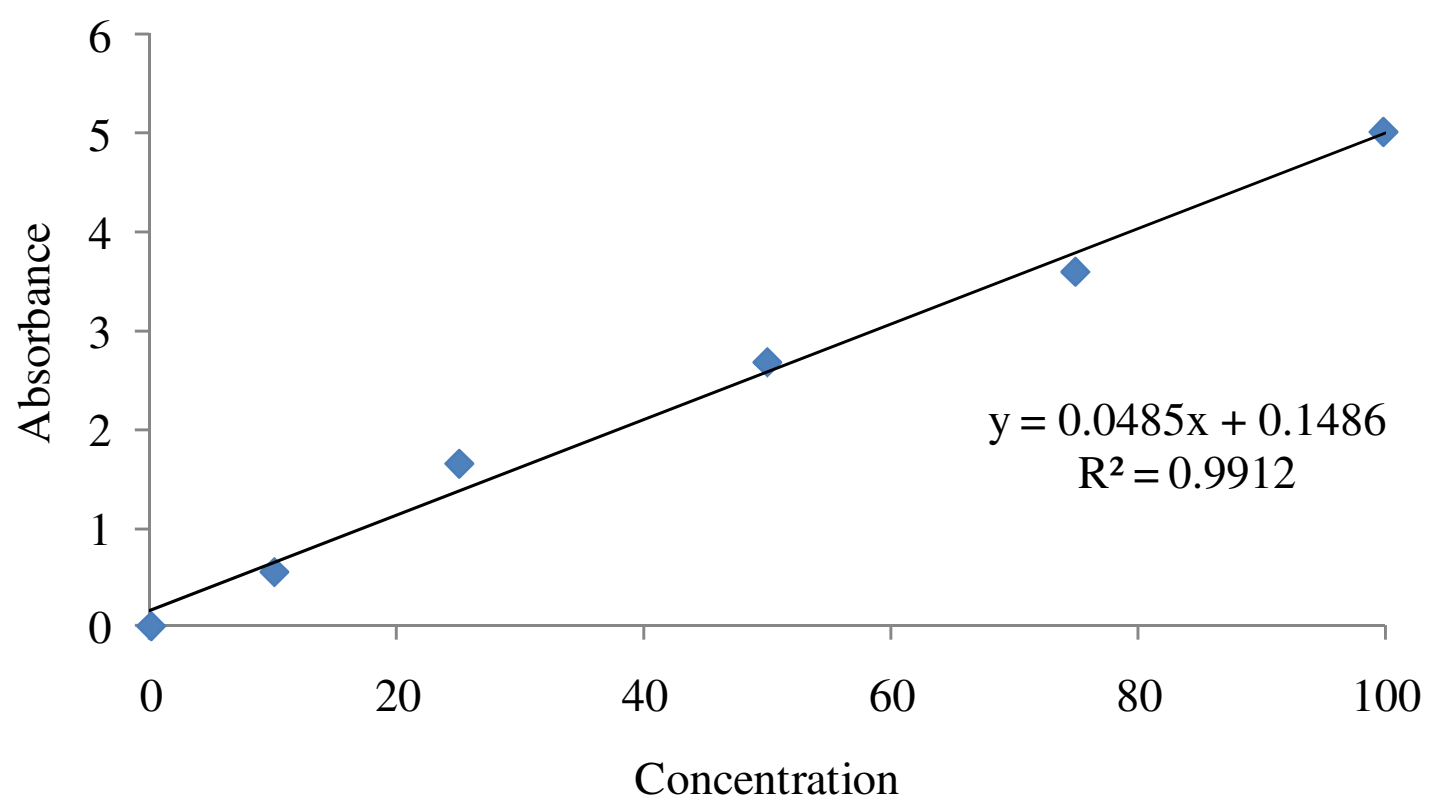

Figure 8. Diagram of a standard curve for malvidin. 